NBER WORKING PAPER SERIES

\title{
SON PREFERENCE, SEX SELECTION AND ECONOMIC DEVELOPMENT: THE CASE OF SOUTH KOREA
}

\author{
Lena Edlund \\ Chulhee Lee \\ Working Paper 18679 \\ http://www.nber.org/papers/w18679 \\ NATIONAL BUREAU OF ECONOMIC RESEARCH \\ 1050 Massachusetts Avenue \\ Cambridge, MA 02138 \\ January 2013
}

Lena Edlund conducted this research in her capacity as an associate professor at Columbia university, No external sources funded this research. The views expressed herein are those of the authors and do not necessarily reflect the views of the National Bureau of Economic Research. Chulhee Lee conducted this research in his capacity as a professor at Seoul National University. His research was supported by National Research Foundation of South Korea (NRF-2010-327-B00094).

NBER working papers are circulated for discussion and comment purposes. They have not been peerreviewed or been subject to the review by the NBER Board of Directors that accompanies official NBER publications.

(C) 2013 by Lena Edlund and Chulhee Lee. All rights reserved. Short sections of text, not to exceed two paragraphs, may be quoted without explicit permission provided that full credit, including (C notice, is given to the source. 
Son Preference, Sex Selection and Economic Development: The Case of South Korea Lena Edlund and Chulhee Lee

NBER Working Paper No. 18679

January 2013

JEL No. J11,J16,O15

\begin{abstract}
$\underline{\text { ABSTRACT }}$
Sex ratios at birth in South Korea reached 116.5 boys per 100 girls in 1990, but have since declined. In 2007, sex ratios were almost normal, a development heralded as a sign that son preference and sex choice have vanished. However, normal sex ratios imply neither. We show that over the last 60 years, the relationship between sex ratios and parental status changed from negative to positive. This pattern, we argue, is consistent with a model where parents prefer sons and sex select - ultrasound and economic development accounting for the change in who chooses sons.
\end{abstract}

\title{
Lena Edlund
}

Department of Economics

Columbia University

1002A IAB, MC 3308

420 West 118th Street

New York, NY 10027

and NBER

le93@columbia.edu

Chulhee Lee

Department of Economics

Seoul National University

599 Kwanak-ro, Kwanak-gu

Seoul, South Korea

chullee@snu.ac.kr 


\section{Introduction}

Normally, about 106 boys per 100 girls are born and there is a very slight tendency for mothers in good condition to have more boys [Almond and Edlund, 2007]. Sex selective infanticide and abortion make for more dramatic deviations, as demonstrated by abnormally male sex ratios in countries such as China and India. Confucianism and Hinduism share not only a unilineal view of descent emphasizing the male line but also lack explicit condemnation of infanticide - the main form of sex selection before the introduction of ultrasound technology in the early 1980s - present in Christianity and Islam.

This paper focuses on South Korea (henceforth Korea), an East Asian country whose demographics have received relatively little attention. In addition to being of interest in its own right, the Korean case may offer a preview of the demographic future of India and China as they progress on their paths of economic growth. As late as the 1960s, Korea was a poor developing country. Korea has not only taken the lead on economic growth, also been ahead demographically. Because of extensive post-natal selection against girls in the 1960s and 1970s and rapidly falling fertility, e.g., Goodkind [1996], the bride shortage now in the works in India and China appeared in Korea already in the 1990s.

Moreover, sex ratios at birth started to climb in Korea following the introduction of ultra-sound technology in the early 1980s. In 1990, 116.5boys per 100 girls were born. Unlike India and China, however, sex ratios have since declined to a normal 106 in 2007, see Figure 1. ${ }^{1}$

\footnotetext{
${ }^{1}$ Korea National Statistics Office, 2007 Annual Report on Live Births and Death Statistics.
} 
Lower sex ratios were greeted with relief by a country increasingly apprehensive of the marriage market consequences of the collective proclivity to sex select in favor of sons. The return to normal sex ratios has also been widely interpreted to imply that son preference and sex selection have been abandoned, ${ }^{2}$ making for a compelling narrative of economic development ushering in gender neutral values and practises [Chung and Das Gupta, 2007].

However, a closer look at the cross-sectional relationship between sex ratios and parental socio-economic status paints a different picture. Using the 2005 census, and restricting our attention to women who had completed fertility (45-74 years old), we find that among those who completed their fertility more recently (those born in the 1950s and reaching age 45 in 1995-2005) sex ratios increased significantly with the mother's education level, going from a below normal sex ratio of 104 sons per 100 daughters for mothers with only primary school education to 112 sons per 100 daughters for mothers with a college degree or higher. However, this positive association is recent. For mothers born in the 1930s and reaching age 45 in 1975-85 and therefore bearing their children largely before the arrival of ultrasound and at a time Korea was still a developing country, the relationship was reversed. Sex ratios were the highest for the least educated mothers and declining with education level to reach normal for college-educated women. The middle cohort, women born in the 1940s, exhibited an essentially flat relationship between sex ratios and education level.

A positive relationship between parental status and maleness of offspring

\footnotetext{
${ }^{2}$ In 2008, the Korean Constitutional Court lifted a 1987 ban on doctors revealing the sex of the unborn child, citing normal sex ratios as evidence that the country had moved beyond son preference and sex selection.
} 
is consistent with a sex choice model where parents prefer sons, but want sons who marry, thus creating derived demand for daughters, in equilibrium supplied by the underclass [Edlund, 1999]. However, such a model cannot account for the erstwhile surplus of males and negative relationship between parental socio-economic status (SES) and offspring sex ratios or the changing pattern observed in Korea.

In this paper, we propose that the cross-sectional and aggregate patterns can be accounted for by changes in the economic environment and sex-selection technologies: economic development and ultra-sound diagnostics.

Children, we propose, provide two types of benefits to parents: psychic utility and material support in old age. Sons are assumed to have higher productivity than daughters. Moreover, sons are assumed to deliver higher psychic utility, but a married daughter is preferred to an unmarried son. This second inequality is important but we believe realistic. For instance, in Confucian teachings the value of a son is closely linked to his having sons, ad infinitum. ${ }^{3}$

When society is poor, the poor in that society may choose sons to support them in old age although these sons would not be able to marry - the aggregate implication of which is a surplus of sons. As society grows richer, even the poor may afford married children. The reason is two-fold. First, assuming decreasing marginal utility of consumption, the additional consumption afforded by an unmarried son is less important at higher incomes, rendering a married daughter (grand-children) more appealing. Second, a richer society likely leads to a higher bride price (assuming children is a normal good for men), reducing the economic disadvantage of daughters. If so, as a society grows richer,

\footnotetext{
${ }^{3}$ If unmarried sons yielded higher psychic utility than married daughters, everybody would be better off with sons only, and the population would rapidly vanish.
} 
the poor may choose daughters who marry over sons who do not, resulting in a decline in the aggregate sex ratio. The substitution of daughters for sons among lower-class parents, in turn, allows for the converse substitution among the upper-class, resulting in the relation between parental status and maleness of offspring to go from u-shaped to positive as society grows richer.

Explicitly allowing for parents to care about consumption and thus the earnings ability of their children (net of marriage transfers, if any) provides a framework for analyzing the impact of development without positing that development acts on the underlying preference for sons (although that is of course a possibility [Chung and Das Gupta, 2007, Lipatov et al., 2008]). Economic development, in our model, influences choices by lowering the valuation of consumption at the margin, which lowers parental valuation of higher earnings potential of sons over daughters, and raises the willingness to pay to have a married son. The higher bride price further contributes to making a married daughter a more attractive option compared to an unmarried son. Lower fertility, would work to strengthen above shift towards favoring children-whohave-children. It can be noted that the total fertility rate in South Korea declined from around 6 in the early 1960s to 1.2 in the 2000s.

Still, the observed pattern in Korea was that of a negative, not a u-shaped, relationship between parental status and offspring sex ratio. How can we understand the absence of the rich selecting sons among women born in the 1930s and bearing children in the 1950s through the 1970s? The explanation for why the poor but not the rich chose sons may lie in the then nature of sex selection before ultra-sound: infanticide or abandonment.

As with the benefits of sons, a psychic and a monetary component can be identified. When the cost of sex selection is primarily psychic, arguably the 
case before ultra-sound, we might expect the rich to abstain. The rich may simply have tolerated unwanted daughters as long as the alternative carried a heavy psychic price tag. Ultra-sound and facultative abortion significantly reduce the psychic cost, encouraging uptake by the better off. Another reason the rich avail themselves of the technology is that they can better afford the procedures, an argument sometimes raised in the context of India and China where it has been found that the more educated and more urbane have higher sex ratios Scharping [2003], Jha et al. [2006]. However, ultra-sound and induced abortion are both relatively simple and cheap, both in absolute terms and relative to the perceived benefits of having a child of the desired sex. ${ }^{4} \mathrm{Be}$ that as it may, the case for the monetary cost being close to insignificant can be made convincingly for Korea, now a rich developed country and a member of the OECD since 1996.

We also present evidence of contemporary sex selection exploiting 2005 Korean Vital statistics. Looking at cross-county variation in sex ratios we find that poor counties, or counties with a high adult sex ratio (ages 20-29, prime marriage years), have lower sex ratios at birth suggesting that current marriage market conditions influence the decision of whether to have a girl or a boy.

The remainder of the paper is organized as follows. We conclude this section by providing a brief literature review (background describing the Korean demographics, marriage market, and institutions for old age support is in the Appendix). Section 2 presents our model of parental sex choice and Section 3 our evidence from Korea. Section 4 concludes.

\footnotetext{
${ }^{4} \mathrm{~A}$ weekly popular magazine reported the cost of sex determination through ultrasound in 1984 at 60,000 won (USD 75) [Park and Cho, 1995].
} 


\subsection{Literature Review}

The arrival of prenatal sex determination in the early 1980s combined with age old preference for sons have resulted in unnaturally high sex ratios (males to females) in a number of Asian countries, including the world's two most populous [Miller, 1981, Das Gupta, 1987, Banister, 1987, Zeng et al., 1993, Tuljapurkar et al., 1995, Scharping, 2003, Zhu et al., 2009]. While normally, 106 boys per 100 girls are born, the 2000 census revealed 120 boys per 100 girls in China. Indian figures reveal similar discrimination against girls, with a sex ratio among juveniles at 116.5to 100 .

These sex ratios have provoked a number of questions as to the motives underlying the proclivity to choose sons and, and by extension, whether this practice will continue in the face of inter alia a mounting surplus of males, moral suasion, and economic development - sex selection being notably absent from developed countries (see e.g., Li et al. [2000], Chung and Das Gupta [2007], Almond and Edlund [2008], Lipatov et al. [2008], Almond et al. [2009]).

This paper's model builds on Edlund [1999], whose main prediction of positive relation between parental status and maleness of offspring under son preference and sex choice coincides with that of the Trivers-Willard hypothesis that natural selection would favor parental ability to adjust sex ratios. Higher status parents would do better choosing sons not because of a preference for sons but because male reproductive success is more resource sensitive than female such. ${ }^{5}$ The marriage market for the key constraint in these studies, giving consumption in old age short shrift.

However, most social-science studies of son preference disregard the marital

\footnotetext{
${ }^{5}$ Thus, son preference is "supported" by natural selection.
} 
prospects of children, positing unconditional preference for sons, e.g., Kim [2005].

The paper's model does not rely on changes to the underlying preference for sons, although that is a possibility. Chung and Das Gupta [2007] analyzed the Korea National Fertility and Family Health Surveys (various years) including questions about about son preference. They found that between 1985 and 2003, there was a marked decline in the fraction of women reporting "must have a son." A difficulty with attitudinal questions, however, is that it is hard to parse the extent to which answers reflects underlying preference or ex post rationalization of choices.

Somewhat ironically, the modeling of the cultural component of son preference and its transmission across generations has been done outside the social sciences. In Li et al. [2000], the son preference is transferred through inheritance (vertically) or from society (obliquely), where the rate of transmission is governed by exogenous transmission parameters. In Lipatov et al. [2008] economic development impacts the cultural preference by effects on the earnings advantage of males. The marriage market feeds back into the cultural value attached to sons because it is assumed that people who prefer sons also choose more sons. Consequently, if mating is random and fertility constant, mothers whose parents had a son preference are under-represented in the next generation.

The assumptions that preferences and choices coincide, and that mating is random set these papers apart from our model which traces out aggregate and cross-sectional implications for sex ratios as a society develops without assuming that development acts on the cultural valuation of sons. Indeed, high sex ratios among South and East Asian immigrants to the U.K. and North 
America suggest that such cultural biases may persist in developed societies [Dubuc and Coleman, 2007, Almond and Edlund, 2008, Almond et al., 2009].

\section{Model}

We model parental sex choice under son preference where parents care about grand-children and old-age support, children's spouses are allocated on monogamous, two-sided marriage market with an endogenous bride-price. We are particularly interested in the role of development for the population sex ratio and who chooses sons and daughters respectively.

Sex choice is assumed perfect but may come at a psychic cost to reflect the reality before ultrasound and prenatal sex choice. Ultrasound is introduced in the early 1980s. Before that, infanticide was the method of choice to ensure the right sex, an act that can weigh on the conscience. ${ }^{6}$ Neither method is free but the monetary cost is nominal, we would argue. ${ }^{7}$

Absent sex choice, sons and daughters are assumed to arrive with 50/50 probability.

\section{Key Assumptions}

1. Sons are more productive than daughters.

\footnotetext{
${ }^{6}$ Abandonment is a sex choice technology that would not affect the population sex ratio, unless abandoned children suffered higher mortality or left the country, in which case abandonment would be similar to infanticide (from a population sex ratio point of view). However, we will focus on sex selection that removes the child from the population.

${ }^{7}$ Sex selection through infanticide entails at least one additional pregnancy and concomitant metabolic needs.
} 
2. Grand-children through sons are more valued than grand-children through daughters.

3. Grand-children through daughters are better than no grand-children.

Assumption 1 also means that no equilibria can have unmarried daughters (if a child remains unmarried, that child would yield higher utility to its parents if male, since more productive). Assumption 2 is in keeping with Confucian tradition. Assumption 3 is based on the evolutionary argument that an all male society is a short lived proposition, and therefore the empirically relevant cases are those which allow for daughters.

The marriage market clears with the help of an endogenous bride price that we will assume is positive. The rationale behind this assumption is that women are mothers by the act of giving birth whereas men become fathers through marriage. The Napoleonic code's succinct summary familial relations - mother is the woman who bears the child, the father is the husband of mother - is near universal, e.g., Posner [1992]. ${ }^{8}$ Marriage not only designates the husband as the father of children borne by the wife but also transfers parental rights from her to him. Thus, a positive valuation of grand-children means that the bride price paid by groom parent to bride parent must be positive.

These simple assumptions deliver a model where, if sex choice is costless, as a society grows richer:

1. The sex ratio declines and asymptotes to $50 / 50$.

\footnotetext{
${ }^{8}$ Historically, the only exception we are aware of is Imperial China where the legal mother of children borne by a concubine was the wife of the concubine's husband. Today, in some jurisdictions, a gestational carrier (surrogate mother) may sign away her right to be designated mother.
} 
2. The cross-sectional relationship between sex ratios and parental SES goes from u-shaped to positive.

When a society is poor, the lowest tier parents choose non-reproductive sons. The remaining parents are divided into two equal-sized tiers, the top tier choose sons who marry the daughters of the second tier.

As society grows richer, the lowest tier can afford to have grand-children and substitute married daughters for unmarried sons. Greater affluence means that the poor are themselves less poor and that the bride price increases.

But when Korea was poor, there was no prenatal sex choice. Thus, to understand the fertility pattern for women born in the 1930s and 1940s it may be instructive to consider the effects of a psychic cost to sex selection.

In that case, the outcome will depend on the magnitude of the cost. Trivially, a sufficiently high cost negates the gains from choice and result in a flat relationship between parental status and offspring sex ratio. At the other end, a low psychic cost results in a softening of the boundaries of the the above described equilibria, where parents close to the cut-off point roll the dice. Inbetween cases may have either the high or the low strata abstain from choosing sons, a decision that affects other parents since the choice to not select sons makes more daughters available. A reason the poor might select sons despite it carrying a psychic cost such that the rest of society abstains (a possible explanation of the negative relationship between maternal education and offspring sex ratio found for women born in the 1930s), is that the marginal utility of the extra consumption afforded by an unmarried son might be very high close to starvation-level consumption. 


\section{$2.1 \quad$ Set Up}

We assume a large, two-sex, population.

Marriage is assumed heterosexual and monogamous, and short hands for children. Marriage is within-cohort and the marriage market clears with the help of a bride price $t$. For simplicity, we assume that each married couple has one child. ${ }^{9}$ We treat the mother and father as a single decision unit and for expositional ease we will refer to it as the parent.

Parents are indexed by $i \in[0,1]$ where parent $i$ 's income is a continuous, increasing, function of $i, y_{i}>y_{j}$, for $i>j$.

Parents strategies are described by the pair $(s, n)$, where $s$ denotes the sex choice $s=\{m, f, n\}, m$ - male; $f$ - female, $n$ - none; and $\mu=\{0,1\}, 0$ - not married, 1 - married, whether the child marries or not, which in the model amounts to whether to buy a son a bride. Since $t>0$, it is always optimal for parents to marry daughters. In the case of no sex selection, $\mu=\{0,1\}$ denotes the whether a son would be given a bride or not.

Consumption depends on exogenous income $y(i)$ and the gender and marital status of children. ${ }^{10}$ We assume that sons earn $\delta$ and daughters zero.

\footnotetext{
${ }^{9}$ This is purely for expositional purposes. An earlier version of the paper assumed two children, which allowed for couples to choose one son and one daughter. Three children would allow for yet more finely granulated outcomes, etc. However, the qualitative flavor of the model would not change. In Section 3 we consider consequences of relaxing the fertility restrictions.

${ }^{10}$ This could be because the parent own the child's income and are responsible for marriage market payments. Alternatively, the parent cares about the earnings power of its child, net of marriage market transfers. In the latter case, one could allow incomes and marriage expenditures to enter as a separate term in utility function, but we opt for the simplifying assumption that parents own their children.
} 
A daughter, however, commands a bride price $t>0$. For simplicity, we assume that women are homogenous as brides, so that the bride price is unique (set by marginal man's willingness to pay for marriage).

Consumption if son marries:

$$
c_{i}=y_{i}+\delta-t
$$

Consumption if son does not marry:

$$
c_{i}=y_{i}+\delta
$$

Consumption if daughter marries:

$$
c_{i}=y_{i}+t
$$

The child also yields psychic benefits. We let $\chi(s, n)$ denote the psychic utility from a child of sex $s=\{m, f, n\}$ and marital status $\mu=\{0,1\} \cdot \chi(n, 0)$ denotes the expected psychic utility from the child if chance is allowed to determine its sex and not marrying the child if a son. Analogously, $\chi(n, 1)$ denotes the expected psychic utility from rolling the dice on the sex of the child, and marrying him.

Parents prefer sons to daughters and married children to unmarried children, and psychic utility from different $(s, \mu)$ pairs are assumed as follows:

$$
0=\chi(m, 0)<\chi(n, 0)<\chi(f, 1)<\chi(n, 1)<\chi(m, 1)
$$

In recognition of the moral and psychological toll of post-natal sex selection, we allow for a psychic cost to sex choice $\psi \geq 0$.

We assume the following quasi-linear utility function, 


$$
u_{i}(\chi, c)=f\left(c_{i}\right)+\chi(s, \mu)-\psi
$$

where $f(c), f^{\prime}(c)>0, f^{\prime \prime}(c)<0, c>0$,

Equilibrium An equilibrium is a set of strategies $(s, \mu)$ such that no parent would obtain higher utility from a different strategy than that chosen.

Definition We will say that society A is more developed than society B (and that $\mathrm{B}$ is poorer than A) if $y_{i}^{A}>y_{i}^{B}, \forall i \in[0,1]$.

We will also use the terms richer and developed synonymously when referring to societies.

\subsubsection{Costless sex selection}

In case sex choice carries no psychic cost, $\psi=0$, all parents sex select and the relevant choices are $(m, 0),(f, 1)$, and $(m, 1)$.

Proposition 1 If $\psi=0$,

1. Equilibria can be described as follows:

$i \in\left[0, i_{1}\right)$ choose $(m, 0)$,

$i \in\left[i_{1}, i_{2}\right)$ choose $(f, 1)$,

$i \in\left[i_{2}, 1\right]$ choose $(m, 1)$.

where $0 \leq i_{1} \leq i_{2}$ and $0<i_{2}<1$.

2. The bride price is positive and makes up at least half of the productivity difference between a son and a daughter.

3. The bride price is higher in a richer society.

Higher bride price implies that (married) daughters become more attractive relative to sons (married or unmarried). 
4. If $0=i_{1}$ characterizes the equilibrium for a society, then equilibria for richer societies are also thus characterized.

That is, if all couples choose children who marries, this would be true in richer societies as well.

5. If $i_{1}>0$ in a society, then $i_{1}>0$ in poorer societies.

That is, if a society has parents choosing unmarried sons, then poorer societies would as well.

Corollary 1 As a society grows richer:

1. The sex ratio declines until it reaches unity and then stays balanced.

2. A u-shaped relationship between maleness of offspring and parental status gives way to a positive relationship.

Corollary 1 is illustrated in Appendix Figure A-3.

Proof:

Intuitively, to see that $0 \leq i_{1} \leq i_{2}<1$, note that the associated choices give successively higher psychic utility and thus must be more expensive (and therefore chosen by successively richer parents).

Bride price. The equilibrium bride price $t$ must be greater than half of the productivity advantage of sons:

$$
t>\delta / 2
$$

Otherwise, a married son, $(m, 1)$, would yield higher monetary returns than a married daughter, $(f, 1)$, and everybody would choose married sons, an impossibility in equilibrium. 
There are two cases to consider: $\delta / 2<t<\delta$ and $t \geq \delta$.

Case 1: $t \geq \delta$.

$t \geq \delta$ is a sufficient condition for a married daughter, $(f, 1)$, to dominate an unmarried son, $(m, 0)$. Consequently, everybody chooses married children, and $i_{1}=i_{2}=0$.

Moreover, in this case, sex ratios must balance, that is $i_{2}=0.5$

To see that an endogenous bride price $t>\delta$ results in a balanced sex ratio, note that if there were too many sons, $i_{2}<0.5$, there would be upward pressure on the bride price, which would raise $i_{2}$. Conversely, if there were too many daughters, $i_{2}>0.5$, downward pressure on the bride price would lower $i_{2}$, a process that would continue until $i_{2}=0.5$ (assuming that $y_{0.5}$ supports a bride price greater than $\delta$ ).

That $i>0.5$ choose sons and $i<0.5$ choose daughters follows from the standard assumption that consumption enters concavely in the utility function and that $y_{i}>y_{j}$, for $i>j$ (while the psychic utility difference between a married son and a married daughter does not). These assumptions also drive the result that, comparing societies, if one society is richer, its bride price would also be higher (point 3).

Case 2: $\delta / 2<t<\delta$. In this case, another type of equilibrium is possible: $i_{1}>0$ and $i_{2}=\frac{i_{1}+1}{2}$.

Here, the bride price does not make up for the productivity difference between a son a daughter. Note that for $(m, 0)$ to be an equilibrium strategy for a subset of the population, we need not only that the poor are poor, but that society is also poor, resulting in a low bride price, $t<\delta$. That $i \in\left[0, i_{1}\right]$ follows from decreasing marginal utility of consumption. The lower psychic utility of an unmarried son compared to a married daughter is offset by higher 
consumption, the utility value of which is the highest for the poor.

For $i_{1}>0$ we need that

$$
\begin{gathered}
f\left(y_{i}+\delta\right)>f\left(y_{i}+t\right)+\chi(f, 1) \Rightarrow \\
f\left(y_{i}+\delta\right)-f\left(y_{i}+t\right)>\chi(f, 1),
\end{gathered}
$$

which clearly can hold for large enough productivity differences between men and women, low enough bride price, low enough valuation of grandchildren from daughters (relative to no grand-children), or some combination of the above.

q.e.d.

\subsubsection{Psychic cost to sex selection}

Allowing for a psychic cost to sex choice can result in a number of different outcomes depending on the magnitude of $\psi$. Clearly, a high $\psi$ reduces the return to choosing sons. If high status parents refrain from choosing sons, this reduces the incentives to choose daughters by lower strata. ${ }^{11}$ The psychic cost of sex-choice cost can be high enough to deter also the poorest from selecting sons in which case nobody sex selects.

A more interesting case is if the cost is such that some fraction still choose unmarried sons. From diminishing marginal utility, those sex selecting would be the poorest. This is not the only possibility, but one of particular relevance for the Korean case. Therefore, we will spell out the conditions under which equilibria are characterized by a segment $i \in\left[0, i_{s}\right]$ selecting unmarried sons and the remaining segment $i \in\left(i_{s}, 1\right]$ choosing reproductive children but

\footnotetext{
${ }^{11}$ Since sons are now from poorer families, the bride price is unlikely to rise.
} 
not their sex, resulting in male biased aggregate sex ratios and a negative relationship between parental status and offspring sex ratio.

Note that society would need to be sufficiently poor for parents to choose unmarried sons over a randomized (no-choice) strategy which in expectation would yield the average of the utility from a married daughter and a married son.

Sufficient conditions for $i \in\left[0, i_{s}\right]$ choosing $(m, 0)$, and $i \in\left(i_{s}, 1\right]$ choosing $(n, 1)$ are that

$$
\chi(m, 1)-\chi(n, 1)<\psi
$$

and that

$$
\psi<\chi(s, 0)-\chi(n, 1)+f\left(y_{i}+\delta\right)-\left(f\left(y_{i}+t\right)+f\left(y_{i}-t\right)\right) / 2 .
$$

Condition 2 ensures that high status parents prefer to not engage in sex selection, the gain from selecting a son is at most $\chi(m, 1)-\chi(n, 1)>0$. For low status parents to sex select, it must be that the gain from so doing exceeds the psychic cost. The gain from selecting a son who does not marry is the difference in consumption $f\left(y_{i}+\delta\right)-\left(f\left(y_{i}+t\right)+f\left(y_{i}-t\right)\right) / 2$ plus the psychic utility loss from not obtaining grand children $\chi(s, 0)-\chi(n, 1)$. Since $\chi(s, 0)-\chi(n, 1)<0$, the bride price must be lower than the productivity advantage of males $t<\delta$ for Condition 3 to hold. From concavity of $f(\cdot)$ we see that the upper bound on $\psi$ increases in lower value of $y_{i}$.

Condition 2 says that for a sufficiently high psychic cost to sex selection, high status parents will not sex select. For sex selection to be undertaken by the poor, Condition 3 also need to hold. Clearly, for sufficiently high marginal utility of consumption Condition 3 holds. In other words, the poor selecting sons and others not sex selecting, resulting in an overall surplus 
of sons and a negative relationship between parental status and maleness of offspring, observed for the cohort of women born in the 1930s, is consistent with a scenario where there is a substantial but not prohibitive psychic cost to sex selection coupled with poverty.

Note that while Condition 3 is likely to hold for a sufficiently poor society, there is no reason to believe economic development bears on whether the better off sex select. Condition 2 may or may not hold. If it does not, the rich finds it worthwhile to sex select and there would be a u-shaped relationship between sex ratios and parental status. Thus, the consideration of a psychic cost to sex selection can explain absence of sex selection by the rich but does not preclude it.

\subsection{Model Discussion}

Our model can account for the decline in the sex ratio seen since the mid 1990s. It does not account for the increase in the sex ratio between 1980-1995, but that increase may be the result of technology diffusion and the fact that early cohorts (with respect to ultrasound) have a "first mover" advantage (since a high sex ratio in their cohort could "force" younger cohorts to more female).

The model elucidates that scarcity of brides does not guarantee that the bride price equalizes the economic returns from sons and daughters, a common feature of poor patriarchal societies [Chung and Das Gupta, 2007]. For married daughters to bring better material rewards than unmarried sons, society needs to be sufficiently rich.

Although sons still are more important than daughters for parents in old age, there are signs that this lopsidedness is on the vane. First, the private 
transfers from children have become increasingly less important source of the elderly income in Korea. Gifts from children accounted for $72.4 \%$ of the income of persons aged 60 and older in 1980; it declined to $31.3 \%$ by $2003 \mathrm{Kim}$ [2010, Table 7.17]. Given that sons (especially the eldest son) make more transfers to parents, this change implies sons became economically less attractive over time. Second, it looks like daughters are now main care-givers for infirm parents in Korea (not daughters-in-law), a reason demand might shift in favor of daughters as society grows richer.

While economic development may affect the extent to which sons are better providers of old age support than daughters (e.g., lower labor-market gender pay gap, emancipation of adult children), we have abstracted from that channel to focus on how higher income affects the valuation of grand-children: the standard assumption of decreasing marginal utility of consumption imply that as a society grows richer, parents' willingness to trade consumption for grand children increases.

\section{Sex Ratios in Korea}

We now present empirical evidence from Korea where rapid economic growth and social insurance programs introduced in the 1970s have allowed for alternative means of old-age security than co-residence with an adult son. Moreover, as in the rest of the world, prenatal sex determination was introduced in the 1980s in the guise of ultrasound imaging.

We start by showing how the relationship between offspring sex ratios and parental social status has changed over the past 60 years, going from a negative to an increasingly positive relationship. 
We then present additional evidence that sex choice is practised in a manner consistent with parents' considering their children's marriage market prospects when deciding the sex of their child: parents, especially low status parents, are less likely to have sons in localities where men face worse marriage market conditions as measured by adult sex ratios. More men than women among adults of marriage age, we argue, is a tell-tale sign of bad marriage market for both men and women, the male sex ratio resulting from women being more upwardly mobile leaving worse marriage-market localities with a literal scarcity of women.

\subsection{Changes Across Cohorts - 2005 Census}

We use a $2 \%$ micro random sample of the 2005 Population and Housing Census (Census, hereafter) to examine the long-term changes in the relationship between offspring sex ratio and parental status. Of the six Censuses taken from 1980 to 2005, for which micro-data random samples are currently available, only the 2005 census provides information on the number of all children ever born by sex, including predeceased children. Thus, the 2005 Census is free from potential biases arising from selective home-leaving patterns that other Censuses are subject to. ${ }^{12}$ Recall bias whereby children abandoned or diseased

\footnotetext{
${ }^{12}$ Infant and child mortality would typically be higher in poorer families than in richer ones. If boys are weaker than girls, as is widely known to be the case, an increase in child mortality means more deaths of sons than of daughters. For this reason, the sex ratio of living children is likely to understate the true sex ratio; and such a downward bias should be larger for poorer families. It is likely that children of poorer parents leave home at a younger age than affluent children. Prior to the 1980s, teenage children of many poor families in Korea, especially those in rural areas, left home to be employed as factory operatives or domestic servants. The direction of bias in the sex ratio in this case depends on whether
} 
in infancy are omitted likely account for the bulk of variation for cohorts bearing the bulk of their children before the 1980s. ${ }^{13}$ It is worth noting that such recall bias attenuates an underestimate of the variation in the sex ratio by parents socio-economic status when sex selection is primarily post-natal, the case before ultrasound. Another advantage of this Census is that the religion of respondents is reported.

A weakness of estimating the offspring sex ratios of multiple cohorts from a single-year census is that only the children of surviving mothers are counted. However, if the mortality of mothers is not strongly correlated with the gender of their children, such a survivorship bias should be small.

We focus on mothers 45-75 years of age in the 2005 census. The reason for limiting the sample to women who had completed child-bearing is two-fold: First, more educated women tend to have children at older age. Second, son preference is more strongly revealed for higher-parity births. ${ }^{14}$ This means that highly-educated women would be more likely to sex select at a relatively older age than the less-educated. Thus, if women still of childbearing age were included in the analysis, the offspring sex ratio of well educated mothers would be underestimated.

Table 1 reports sex ratios by maternal education for the three successive children of a particular sex were more likely to leave home earlier, which is unclear. If daughters tend to leave home earlier than sons, for example, the sex ratio of children living with parents would overstate the true sex ratio; and this upward bias would be greater for poorer families than for richer families.

${ }^{13}$ The naturally occurring variation in sex ratios at birth is small [Almond and Edlund, 2007]

${ }^{14}$ For example, whereas the overall sex ratio in Korea was 117.2 in 1990 , the sex ratio of the third-parity children was 195.9, and those of fourth- and fifth-parity children were 234.4 and 228.8 , respectively. 
ten-year cohorts 1931-1940, 1941-1950, and 1951-1960 respectively. The top panel reports by education level. For the women born between 1931 and 1940, the offspring sex ratio falls monotonically with maternal education. Women with primary education of less reports 1.098 boys per girls whereas for women with a college degree, the sex ratio was a normal 1.05. The relationship between mother's education and offspring sex ratio remains negative for the cohort born in the next decade (1941 to 1950), but is substantially flatter. Finally, for the youngest cohort of women who had completed fertility in 2005, those born between 1951 and 1960, the relationship is positive. The least educated reported a sex ratio of 1.044 whereas mothers with a college degree or more had borne 1.115 sons per daughter. Using father's education instead of mother's as a measure of parental status provides similar results. ${ }^{15}$ Figure 2 illustrate this changing pattern.

The education distribution changed dramatically for these cohorts. For instance, women with primary school or less made up 21 percent of the 1951-60 cohort, down from 82 percent among the 1931-40 cohort, and college education among women grew from 2.2 percent among the older cohort to 14 percent among the younger. Therefore we group each birth cohort into three educational categories in an attempt to make each cell size as similar as possible. The results are presented in the lower panel of Table 1 and (as expected) are qualitatively similar to those in the upper panel.

The timing of the changes are in line with the predictions of the model.

\footnotetext{
${ }^{15}$ The offspring sex ratio of the least educated fathers fell from 1.085 for the 1931-1940 cohort to 1.056 for the 1951-1960 cohort, whereas the ratio of sons to daughters of the collegeeducated fathers increased from 1.065 for the 1931-1940 cohort to 1.132 for the 1951-1060 cohort.
} 
The the 1931-1940 cohort bore their children in the 1950-1980 period. Since Korea was a much poorer country then and there were no public transfer programs in place, economic considerations may have played a major role in the decision whether to favor sons or daughters. On the other hand, women born in the 1950s did the bulk of their childbearing in the 1970-1995 period, a quarter century that saw per-capita income increase by 13 times and the establishment of major social welfare programs. Thus, the 1951-60 cohort was perhaps the first who could anticipate other means of old-age support than co-residence with adult sons.

\subsection{Changes Across Cohorts - 1993-2009 Vital Statis- tics}

A disadvantage of restricting the analysis to women who have completed child bearing is that the picture that emerges is dated. To see how the relationship between parental SES and offspring sex ratios has changed more recently, we analyzed Vital Statistics micro data on births from 1993 to 2009. More specifically, we estimated the effects of parental education and occupation affected offspring sex ratio, and compared the results between children born in the two sub-periods: 1993 to 2000 and 2001 to 2009.

As is noted earlier, estimating the effect of parental SES on offspring sex ratio based on the data on mothers still of childbearing age could be subject to bias problem. To mitigate this problem, we hold mother's age and birth parity constant by conducting regression analyses.

Mother's education and father's occupation are used as measures of parental 
socioeconomic status. ${ }^{16}$ It is difficult to determine the SES of parents based on mother's occupation, because the vast majority of mothers are not working at the time of childbirth. Mother's education is classified into the following three categories: (1) college or higher (control group), (2) high school, and (3) middle school or lower. ${ }^{17}$ Father's occupation is divided into the following four categories: (1) white-collar (including professional and clerical jobs), (2) service and sales, (3) higher blue-collar (skilled workers), and (4) lower bluecollar (unskilled workers). A very small number of farmers and those whose occupation is missing are excluded from the analysis.

We conducted logistic regressions to examine the correlates of the probability that a given child is male.

$$
P_{i}^{s o n}=\alpha+\beta S E S_{i}+A G E_{i}+P A R I T Y_{i}+P R O V I N C E_{i}+Y E A R_{i}+\epsilon_{i},
$$

where $P_{i}^{\text {son }}$ denotes the probability that the child is male; SES is a vector of dummies measuring parental status, education of the mother or occupation of the father; AGE is mother's age; PARITY is a vector of dummy variables for birth parity; PROVINCE is a vector of dummy variables for province or metropolitan city of birth; and YEAR is a vector of dummy variables for the year of birth. $\beta$ is the vector of coefficients we are interested in, and we expect lower SES to be associated with lower probability of a son.

\footnotetext{
${ }^{16}$ Father's occupation could not be used as a measure of parental SES for older cohorts because a large fraction of fathers had retired by 2005.

${ }^{17}$ Among younger female cohorts who gave a birth between 1993 and 2009, there are few persons with primary school education or lower. The lowest education category (including no education, primary school, and middle school) accounts for only $2.6 \%$ of the sample for the years 2001 to 2009. Therefore, we did not make any further breakdown.
} 
To examine if the relationship between parental SES and offspring sex ratio changed over time, we estimate Equation 4 for the two sub-periods 1993 to 2000 and 2001 to 2009 .

The regression results are reported in Table 2, panel A (mother's education) and panel B (father's occupation). Figures 3 and 4 graphically present SES gradients in the probability that the child is a boy, with the probabilities for the top SES categories normalized into 100. For both periods, parental SES is positively associated with the probability that the newborn child is a boy. Compared to a child of the top SES family (college-educated mother and white-collar father, respectively), a child born to a less-educated mother or to a lower-occupation father were significantly less likely to be male; and the absolute magnitude of the coefficient for each SES category follows its hierarchical order.

More importantly, as clearly seen from Figures 3 and 4, SES gradients of the offspring sex ratio became steeper from 1993-2000 to 2001-2009. For example, from 1993 to 2000, children born to mothers with middle school education or lower were about $2.8 \%$ less likely to be male; for the period 2001-2009, the difference between the top and bottom educational categories increased to $3.2 \%$.

Another noteworthy pattern is that the influence of birth order is weakened, consistent with lower fertility and a compression of the distribution (lower status mothers still bear more children, but less so than in the past).

The results of the regression analysis are consistent with the conclusions drawn from the records of completed fertility of older female cohorts. If mother's age and birth order of the child are controlled for, the relationship between parental SES and the offspring sex ratio is positive for more recent 
female cohorts. Furthermore, it looks like the long-term shift in the relationship between parental SES and offspring sex ratio at birth continued in recent years.

\subsection{Marriage Market Influences on Sex Ratios at Birth}

Our model assumes that parents take their children's marriage market prospects into account when evaluating respective benefits of sons and daughters. In this section we seek to provide some evidence of such a mechanism.

Faced with the rather complex task of forecasting not only overall marriage market conditions two to three decades hence, but also a son's competitiveness, parents likely resort to a heuristic. One possible heuristic would be to take the local sex ratio among adults of marrying ages as a signal of future marriageability of a son.

Seemingly, the local sex ratio of young adults bears little relation to the marriage market a generation hence. Competition in the marriage market tends to be with members of adjacent cohorts, not the parent generation. Would the juvenile (0-5) sex ratio not be more relevant?

One argument for why the adult (local) sex ratio would contain better information about future marriage market prospects for today's sons in that locality is that if the marriage market is national, the local sex ratio may be informative of current local marriage market conditions. For instance, if the area is relatively poor (assuming that low income men are less attractive spouses), young women may move out of the area in order to marry men in richer areas. The scope for such migration would amplified in a country with an overall deficit of brides. Thus, a local male sex ratio among young adults 
could reflect young men finding it particularly difficult to marry. Certainly, men may also migrate but not for marriage reasons. The argument being that men pay for marriage, so that for men marriage is an expense, while for women (under individual consent regimes), marriage is a source of income, e.g., Edlund and Korn [2002]. Assuming that the labor market in richer areas does not offer higher returns to women worker than men workers, differential out migration of young women reflect that men in that area compare poorly to men in other areas, one of us argued in Edlund [2005].

By contrast, variation in the juvenile sex ratio would reflect parental sex choice in the recent past. Choices made based on information available at the time. Thus, the juvenile sex ratio could may be a dated indicator of beliefs about the future marriage market.

For our empirical analysis we consider the relationship between the local (county or district) sex ratio of newborns and the sex ratio of 20 to 29 yearolds. The ages 20 to 29 were chosen because they constitute key marriage ages. (Interestingly, we did not find effects for the flanking ages, the 10-19 or the 30-39 age groups, not reported.)

Sex ratios at birth for each county (or district) were computed from the micro data on the 2005 Vital Statistics for Birth and Death. The 20 to 29 sex ratio was calculated using the $2 \%$ sample of the 2005 Census. The 2005 Census was also used to calculate the fraction Buddhists, Protestants, and Catholics in each locality. Finally, average earnings of employed males aged 20 to 55 in each locality were calculated using micro data from the 2005 Occupational Employment Statistics (OES).

There were 327 counties and districts in 2005. Of these localities, 249 were selected based on the following criteria: first, the total number of births was 
100 or more (253 counties and districts satisfy this condition), and second, the variables on the sex ratio of younger adults, religion, and earnings from the Census and the OES are all complete. ${ }^{18}$

We consider the following sex ratios at birth: (1) the overall sex ratio, (2) the sex ratio of second- or higher-parity births, (3) the sex ratio of children born to high-education mothers (those with college education or higher), and (4) the sex ratio of children born to low-education mothers (those with high school education or lower). Since discrimination against girls has been found to be particularly pronounced at higher parity and absent sons, e.g., Das Gupta [1987], Zeng et al. [1993], Jha et al. [2006], Almond and Edlund [2008], the relationship between the sex ratio and marriage market condition, if any, could be more strongly revealed for higher-parity births. ${ }^{19}$ The third and fourth variables are considered to examine if the relationship between offspring sex ratio and marriage market prospect differs by parental status. With non-random marriage market matching, sons of poorer parents would be more vulnerable to an aggregate shortage of brides, which may make poorer parents's sex choice more sensitive to the local sex ratio.

Figure 5 plots the relationship between the county sex ratios at birth and the sex ratio of the residents of marriageable age. The overall sex ratio at birth is negatively related to the sex ratio of young adults, suggesting that parents are less likely to choose sons in counties where marriage-market prospects

\footnotetext{
${ }^{18}$ While it would be useful to look into the male and female earnings separately, the relatively modest sample size of the OES (about 60,000 employees in total) makes it difficult to estimate average earnings in each county (or district) for females.

${ }^{19}$ Although the overall sex ratio at birth has recently returned to a normal level in Korea (106.1 in 2007), the son-to-daughter ratio for the third or higher parity births remains still high (115.7 in 2007).
} 
for males are poorer. This negative relationship stands out more clearly for second- and higher-parity births, consistent with existing evidence of sex selection being more pronounced at higher parity (top-right panel). For bettereducated mothers, the local marriage-market condition does not appear to matter much for offspring gender (lower-left panel). For low-education mothers a stronger influence of marriage market condition on sex ratio at birth is observed (lower-right panel). This is consistent with non-random marriage market matching: sons of poorer parents would be more vulnerable to an aggregate shortage of brides (rendering poorer parents's sex choice more sensitive to the local sex ratio).

\subsubsection{Regression Results}

The local adult sex ratio is only one predictor of a son's future marriage market. Therefore, we now turn to regression analysis and estimate by OLS the following regression equation:

$$
\operatorname{ratioO}_{i}=\operatorname{ratio}_{2029_{i}}+\ln y_{i}+x_{i}+\epsilon_{i}
$$

where $i$ subscript indicates the county (or district), ratio $0_{i}$ is the sex ratio at birth, ratio2029 $i$ is the sex ratio of 20-29 year olds, and $\ln y_{i}$ is the log of the average male earnings in the county. These latter two variables are indicators of marriage market conditions, where we expect higher 20-29 sex ratios and lower male earnings to lower the sex ratio at birth.

We control for the fraction Christians, $x_{i}$, to capture possible religious or cultural influences on son preference and attitudes towards abortion. Chung [2007] found Christians to be significantly less likely to have used induced abortion to screen out girls in her analysis of the 2000 Korea National Fertility 
and Family Health Survey, a finding echoed in Almond et al. [2009]'s study of Asian immigrants to Canada using the 2001 Canadian Census.

In alternative specifications we also include variables meant to capture the relative desirability of sons: female relative to male employment and the housing value in the locality. We expect higher female to male employment to lower the sex ratio to the extent it indicates higher female to male labor market productivity. The effect of housing values are ambiguous for a number of reasons. Economically prosperous areas have higher housing values, and to the extent not captured by the other controls, we would expect a positive relationship between housing values and sex ratios. All things equal, however, higher housing values would make daughters more attractive because traditionally the parents of the groom are responsible for housing the newly weds.

We estimate Equation 5 for the four sex ratios described above: all births, second and higher order births, non-college mothers, and college mothers.

The results are reported in Tables 4 and 5. Table 4 presents results for all births (upper panel) and second and higher order births (lower panel). Table 5 divides the sample by mothers education.

In the first column, only the adult sex ratio, income of the locality (as measured by earnings), and the share Christian are included. In the second column, we add the female to male employment ratio as an index of crosssectional variation in the relative productivity of daughters. In the third column, housing value is substituted for the female to male employment level. In the fourth column, we use the share of single men among men aged 35-44 instead of the 20-29 sex ratio as an alternative measure of the marriage market. The choice of this variable is motivated by the observation that a (growing) bride shortage likely affects the share of men who remain unmarried in their 
late 30s and early 40s (a share that has risen rapidly in the last decade).

Throughout, the share of Christians in the population has a strongly negative and highly statistically significant impact on sex ratios and in the interest of space we omit presenting the coefficients (available on request).

Our main variables of interest, however, are the 20-29 sex ratio and county earnings. As hypothesized, a high 20-29 sex ratio lowers the sex ratio at birth except for college educated mothers (lower panel, Table 5). The negative effect is statistically significant at conventional levels and more pronounced at higher parities (lower panel, Table 4) and for more marginal mothers (top panel, Table 5). The effect size is also significant. Since the adult sex ratio is driven by migration, there is a fair amount of variation, the standard deviation being 0.277 . For second or higher order births, the estimates suggest that a county with a 20-29 sex ratio of 1.5 would have a five percentage points lower sex ratio at birth than a county with a 20-29 sex ratio of 1 .

We include earnings as a proxy for the economic standing of a county. There are two counter balancing ways income of a county affects sex ratios. On the one hand, they proxy for the economic motive for parents to prefer sons and we would expect lower income counties to choose more sons. On the other hand, lower income also implies a disadvantage in the national marriage market, and from this mechanism we would expect lower income counties to have less male sex ratios. While the coefficient on earnings is generally positive, the effect is not statistically significant (except for non-college mothers, column 1, top panel, Table 5).

The ratio of female to male employment rates is added to the baseline model as an index of cross-sectional variation in the relative productivity of daughters. It has reasonably strong negative effect on the offspring sex ratio, 
especially of higher-order births (lower panel, column 2, Table 4) and of loweducated parents (top panel, column 2, Table 4), consistent with the prediction of the model.

As for housing value, the results are mixed. Higher value depresses the male to female ratio except for college educated mothers, but the effect is only statistically significant for higher-order births (column 3, Tables 4 and 5).

Finally, as an alternative measure of the local labor market, we substitute the share who are single among 35-44 year-old men, and find similar results. A higher singles share depresses the sex ratio at birth except for college educated mothers. The main difference is that the effect of average earnings loses significance further, perhaps due to the fact that men in poorer areas are more likely to remain unmarried through middle age (the coefficient of correlation between the share of single among 35-44 year-old men and log of county average earnings is $-0.451, p$-value $<0.0001)$.

The one group for whom poor local marriage market conditions does not seem to have a bearing on the sex ratio is college educated women. A possible reason is that both sons and daughters of the better educated are socially and geographically mobile to the point of rendering local marriage market conditions irrelevant. Another possibility is that the college educated in poor places are relatively even more elite, a factor could countervail the effects of being in a disadvantaged area.

\subsubsection{Robustness}

A question that arises from the baseline results is whether the outcomes merely reflect an urban-rural divide unrelated to the influence of marriage market condition on sex selection. For instance, rural areas are not only poorer than 
urban areas but also has worse infrastructure, so that rural resident's access to prenatal ultrasound examination is worse.

However, the results of additional analysis (reported in Appendix Table A-9) suggest that not to be the case. The baseline results remain largely unchanged if the size of population aged 15 to 44 or the total number of births is controlled for (See Panels A and B). In addition, regression analysis for the following three subsamples of counties and districts: counties and districts excluding those in Seoul (Panel C), counties and districts in non-metropolitan areas (Panel D), and districts in metropolitan areas (Panel E). The results for the first two (more rural) samples are largely similar to the baseline results. The results based on the third (urban) sample depend on the choice of the measure of marriage market condition. If singlemale3544 is included, the results are similar to those of the baseline regressions. If ratio2029 is included, it is substantially different. As will be discussed below, it is perhaps because the district in metropolitan cities is too narrow a unit of the marriage market (or the unit of areas within which the expectation of the children's future marriage-market prospect is formed).

Another question is if county or district is an appropriate unit for analyzing the effect of marriage-market condition, as implicitly assumed in this study. More specifically, the question is whether the choice of offspring sex of parents living in a particular county (or district) is determined only by the conditions within the administrative unit. It perhaps depends on the characteristics of the place. For example, districts in urban areas are relatively small in size, and probably more highly integrated with neighboring places. If so, the relevant area for marriage market information could extend beyond the district (or county). Therefore, the county (or district) level may be appropri- 
ate for smaller rural places, while for large metropolitan area, a more inclusive geographic grouping might make sense.

Motivated by this conjecture, we construct a new dataset including variables on marriage-market conditions of neighboring counties or districts. For instance, a_ratio2029 for county $j$ is calculated by dividing the number of males 20 to 29 years of age by the number of females in the same age group in county $j$ and all contiguous counties. Another measure of marriage market condition, a_singlemale3544, is constructed similarly.

For the sample of metropolitan cities, regressions employing the wider definition of marriage market (Panel G, Appendix Table A-9) provide much more promising results than those based on the original variables on marriagemarket conditions. The new results are generally similar to the baseline results. The main exception is that the sex ratio of higher-parity births is not significantly influenced by the measures of marriage-market condition, perhaps reflecting the fact that relatively few births in urban areas in 2005 were second or higher-parity births.

In contrast to the metropolitan sample, the wider definition of marriage market does not work well for the sample of non-metropolitan areas (Panel F, Appendix Table A-9). The coefficients for the marriage market variables are all insignificant and different in sign from those of the baseline results.

In sum, parental decisions on offspring sex in large metropolitan areas appear to be affected by the circumstances in neighboring districts and cities, whereas those in countryside are largely influenced by the conditions within the administrative unit.

These findings also provide an explanation for the relatively poor performance of the baseline regressions for the urban sample reported above. 


\subsubsection{Evidence on Partner Search Being Local}

It is assumed in this study that county/district is a geographic unit within which parents gather information for forming expectation about their childrens marriage market condition in the future. This assumption does not require that county/district is the actual unit of marriage market. If a large fraction of people actually find their spouses within the boundary of their county/district of residence, the assumption behind using the geographic unit will be more strongly justified.

We have attempted to estimate what fraction of the couples who reported their marriage in 2005 had lived in the same county or district before they got married. The Vital Statistics on marriage, compiled from marriage registration records, provide information on the places of residence where brides and grooms lived. The official guideline for marriage registration asks to report the address that is given in the current Residence Registration Record. When a person transfers to a new household because of marriage, she/he is required to report the change to a local office, with the reason for the change, such as marriage. It is thus likely that people report marriage first, and then transfer to a new household later.

By comparing the addresses of brides and grooms given in the Vital Statistics, we computed what fraction of couples who reported their marriage in 2005 lived in the same geographic unit. The Col. (1) of Table A-8 suggests that more than half $(52 \%)$ of newly-married couples lived in the same country or district. The fraction of couples from the same county or district was higher for those whose husband lived in non-metropolitan areas (59\%) than those from metropolitan areas. The result remains true if wifes address is used 
for determining the residence in metropolitan areas. It is probably because districts in urban areas are relatively small in size, and more highly integrated with neighboring places. The results also show that three out of four couples lived in the same city or province according to this measure. It appears quite rare that a man and a woman from two different regions meet and marry in Korea.

As noted, it is not entirely evident whether the address given in the Vital Statistics refers to pre-marital place of residence. It is possible that some couples, especially those who register their marriage long after the beginning of cohabitation, report their post-marital address. If this is the case, the percentage of couples who lived in the same county/district prior to marriage given above should be overestimated.

Additional pieces of information reported in the Vital Statistics, namely, the dates of actual marriage (or beginning of cohabitation) and of marriage registration, offer an opportunity to determine the magnitude of this potential bias. About $14 \%$ of all newly-married couples reported marriage before they married (or started cohabitation). Given the rules for public registrations, it should be difficult for these couples to report the post-marital address on marriage registration. It is unknown why they made pre-registration. But a couple living away from each other prior to marriage would have a greater incentive to do so, because post-registration would be more costly because of longer distance between pre-marital and post-marital places of residence. For these reasons, potential upward bias should be smaller, if any, for this group of couples. 


\section{Summary and Discussion}

Sex ratios returned to close to normal levels of 1.06 boys per girls in the mid 2000, down from 1.17 in 1990, a development that has been taken as a sign that economic development has brought an end to son preference and sex selection. However, a closer look reveals a pattern to sex ratios consistent with continued son preference and sex selection: positive correlation between maternal status and maleness of offspring. Furthermore, this is a new development. For mothers born in the 1930s - bearing their children before ultrasound and Korea joining the ranks of developed countries - the relationship was the reverse. Low education mothers reported more sons (relative to daughters) than better educated mothers. The changing pattern, we have argued, can be understood in light of the changing nature of sex choice. Before ultrasound, sex choice entailed infanticide or abandonment of offspring, acts that are nominally free but can weigh on the conscience.

We have provided a theoretical framework for analyzing the impact of economic development on parental sex choice when sons are culturally prized and children provide old age support. Two key assumptions drive our model. First, the cultural valuation of children vary not only with gender but also with marital status. In particular, while a married son is preferred to a married daughter, she is preferred to an unmarried son. Second, we assume that parents of higher social standing are more likely to be able to marry their son than parents of low status. We use the model to trace out predictions for how sex ratios would vary over time and cross sectionally with economic development. We have also presented corroborative evidence data from South Korea, a country which shares with India and China a strong patriarchal cul- 
ture favoring sons, and a recent past of poverty. Korea went from being a poor developing country in the 1960s to joining the OECD in 1996.

Explicitly allowing for parents to care about consumption and thus the earnings ability of their children net of marriage transfers (if any) provides a framework for analyzing the likely impact of development without positing that it acts on cultural motives for son preference. Economic development, in our model, directly influences choices by lowering the valuation of consumption at the margin, which lowers parental valuation of higher earnings potential of sons over daughters, and raises the willingness to pay to have a married son. The higher bride price, in turn, contributes further to making a married daughter a more attractive option compared to an unmarried son.

There are of course other avenues through which development may reduce the material advantage of sons. Less emphasis on physical strength and lower desired fertility, the earnings gender gap may close. Moreover, with the adoption of more individualistic values, parents' claim on their children's labor may be lessened (possibly facilitated by growing importance of wage work), further reducing the importance of differential earnings by gender. Working age adults are pulled away from co-residence with their parents through the process of urbanization, migration and lower importance of land in the production process.

Moreover, we find, in the cross-section, that marriage market conditions have a bearing on parents' sex choice using vital statistics and census data from 2005. Poor counties, or counties with a high sex ratio among adults 20-29, had lower sex ratios at birth, suggesting that current marriage market conditions may impact the decision of whether to have a girl or a boy.

If parents consider the sex ratio among those of marrying ages, and not of 
younger ages, when choosing the sex of their child, this could contribute to our understanding of why in the case of China, despite more than two decades of growing deficit of girls, parents continue to select boys.

The role of the marriage market in tempering the proclivity to select sons may also contribute to the understanding of the recent findings of high offspring sex ratios among Asian immigrants in a number of Western countries [Dubuc and Coleman, 2007, Almond and Edlund, 2008, Almond et al., 2009] - being of high socio-economic status and forming minorities in their host countries, these groups can run a significant deficit of females without compromising their sons' ability to marry.

However, the paper's main contribution is to present evidence that despite close to normal sex ratios in the aggregate and Korea being an advanced developed country, sex selection is still widely practised.

\section{References}

Douglas Almond and Lena Edlund. Trivers-Willard at birth and one year: Evidence from U.S. natality data 1983-2001. Proceedings of the Royal Society B: Biological Sciences, 274:2491-2496, 2007. Published online August 8.

Douglas Almond and Lena Edlund. Son biased sex ratios in the U.S. 2000 census. Proceedings of the National Academy of Sciences, 105(15):56815682, April 152008.

Douglas Almond, Lena Edlund, and Kevin Milligan. Son preference and the persistence of culture: Evidence from Asian immigrants to Canada. Working 
Paper 15391, National Bureau of Economic Research, October 2009. URL http://www . nber .org/papers/w15391.

Judith Banister. China's changing population. Stanford University Press, 1987.

Woojin Chung. The relation of son preference and religion to induced abortion: The case of South Korea. Journal of Biosocial Science, 39:707-719, 2007.

Woojin Chung and Monica Das Gupta. The decline of son preference in South Korea: The roles of development and public policy. Population and Development Review, 33(4):757-783, December 2007.

M. Das Gupta, Jiang Zhenghua, Li Bohua, Xie Zhenming, Woojin Chung, and Bae Hwa-Ok. Why is son preference so persistent in East and South Asia? a cross-country study of China, India and the Republic of Korea. Journal of Development Studies, 40(2):153-187, 2003.

Monica Das Gupta. Selective discrimination against female children in rural Punjab, India. Population and Development Review, 13:77-100, March 1987.

Sylvie Dubuc and David Coleman. An increase in the sex ratio of births to India-born mothers in England and Wales: Evidence for sex-selective abortion. Population and Development Review, 33(2):383-400, June 2007.

Lena Edlund. Son preference, sex ratios, and marriage patterns. Journal of Political Economy, 107(6):1275-1304, December 1999.

Lena Edlund. Sex and the city. Scandinavian Journal of Economics, 107: 25-44, 2005.

Lena Edlund and Evelyn Korn. A theory of prostitution. Journal of Political Economy, 110(1):181-214, February 2002. 
Daniel Goodkind. On substituting sex preference strategies in East Asia: Does prenatal sex selection reduce postnatal discrimination. Population and Development Review, 22(1):111-125, March 1996.

Prabhat Jha, Rajexh Kumar, Priya Vasa, Neeraj Dhingra, Deva Thiruchelvam, and Rahim Moineddin. High male-to-female sex ratio of children born in India: national survey of 1.1 million households. The Lancet, (January 21): 211-218, 2006.

Hisam Kim. Intergenerational Transfers and Old-Age Security in Korea. In Takatoshi Ito and Andrew Rose, editors, The Economic Consequences of Demographic Change in East Asia, volume 19 of NBER Book Series East Asia Seminar on Economics. NBER, University of Chicago Press, 2010. Conference held June 19-21, 2008.

Jinyoung Kim. Sex selection and fertility in a dynamic model of conception and abortion. Journal of Population Economics, 18:4167, 2005.

Nan Li, Marcus W. Feldman, and Shuzhuo Li. Cultural transmission in a demographic study of sex ratio at birth in China's future. Theoretical Population Biology, 58:161-172, 2000.

Mikhail Lipatov, Shuzhuo Li, and Marcus W. Feldman. Economics, cultural transmission, and the dynamics of the sex ratio at birth in China. PNAS, 49(105):19171-19176, December 92008.

Barbara D. Miller. The Endangered Sex: Neglect of Female Children in Rural North India. Cornell University Press, Ithaca, 1981. 
Chai Bin Park and Nam-Hoon Cho. Consequences of son preferences in a lowfertility society: imbalance of the sex ratio at birth in Korea. Population and Development Review, 21(1):59-84, March 1995.

Richard Posner. Sex and Reason. Harvard University Press, Cambridge, MA, 1992.

Thomas Scharping. Birth Control in China, 1949-2000: Population Policy and Demographic Development. Routledge, London and New York, 2003.

Shripad Tuljapurkar, Nan Li, and Marcus W. Feldman. High sex ratios in China's future. Science, 267:874876, February 1995.

Yi Zeng, Ping Tu, Baochang Gu, Yi Xu, Bohua Li, and Yongping Li. Causes and implications of the recent increase in the reported sex ratio at birth in China. Population and Development Review, 19(2):283-302, 1993.

Wei Xing Zhu, Li Lu, and Therese Hesketh. China's excess males, sex selective abortion, and one child policy: analysis of data from 2005 national intercensus survey. British Medical Journal, 338, 2009. 
Figure 1: Sex Ratio at birth by year

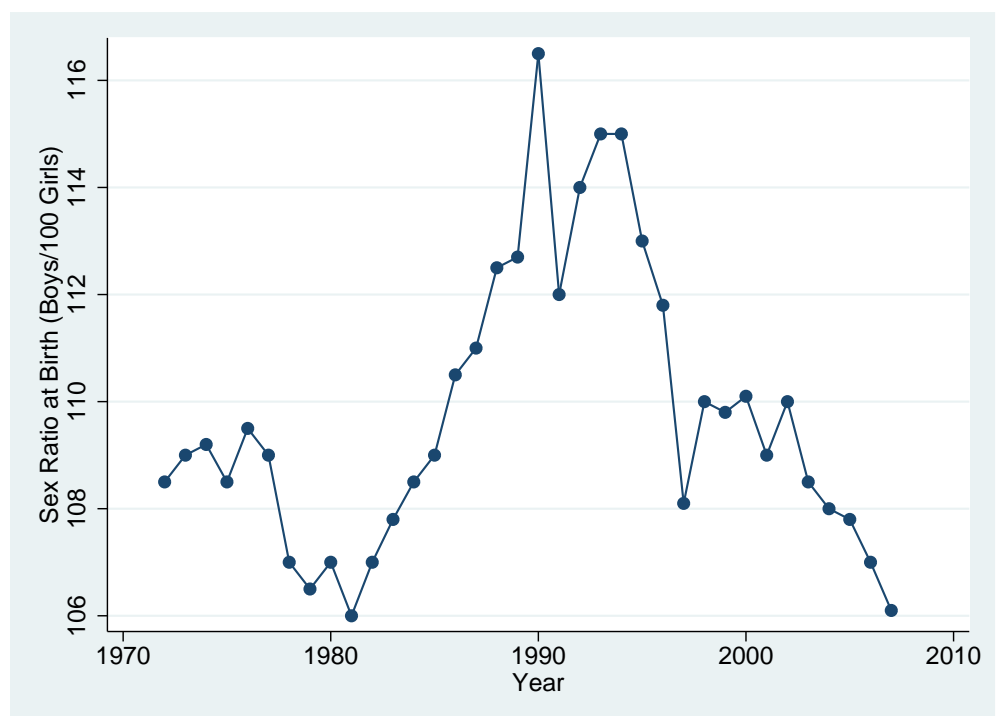

Source: Goodkind [1996] and http://atlas.ngii.go.kr/english/ explanation/social_3_1.jsp

Figure 2: Offspring Sex Ratio Mothers 45 Years or Older, by Mother's Education and Cohort.

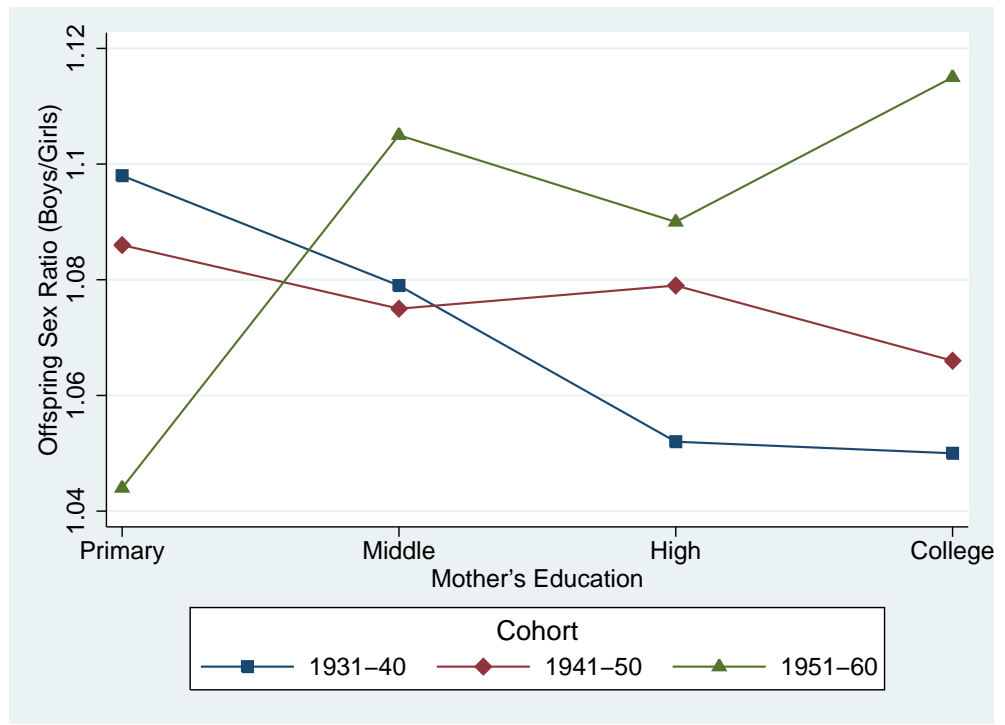

Source: $2 \%$ micro sample of the 2005 Korean Census. 
Figure 3: Probability of Son Relative to College Educated Mothers, by Mother's Education and Over Time.

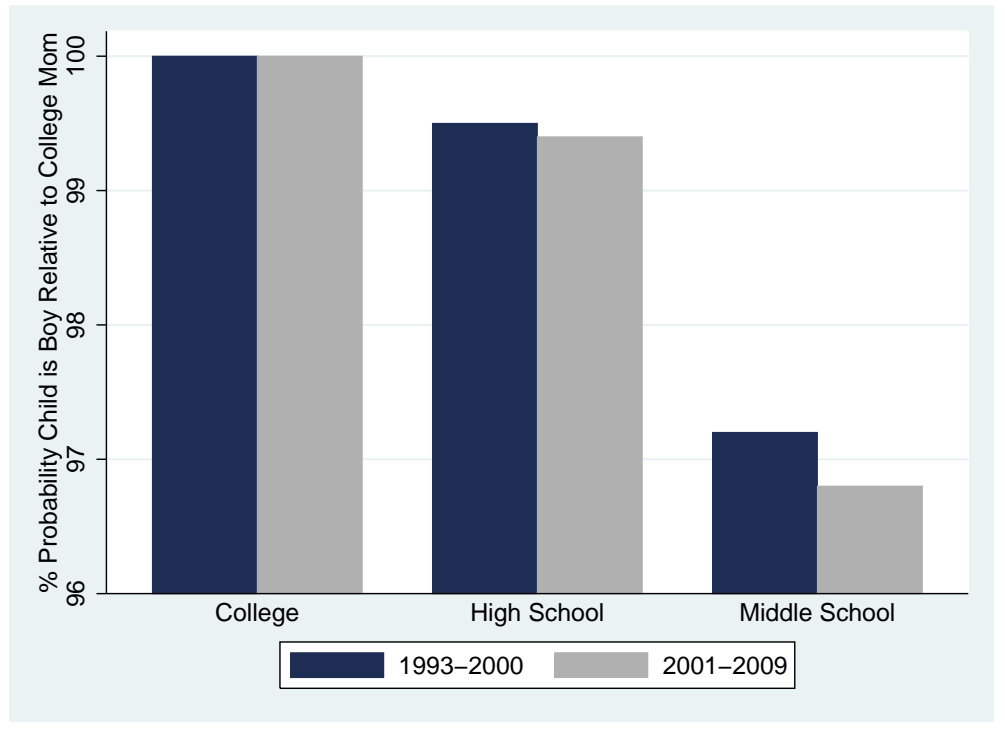

Note: The figure graphs the conditional probability of a son corresponding to Equation 4, also presented in Table 2.

Source: Micro data from Korean Vital Statistics, 1993-2009.

Figure 4: Probability of Son Relative to White-collar Father, by Father's Occupation and Over Time.

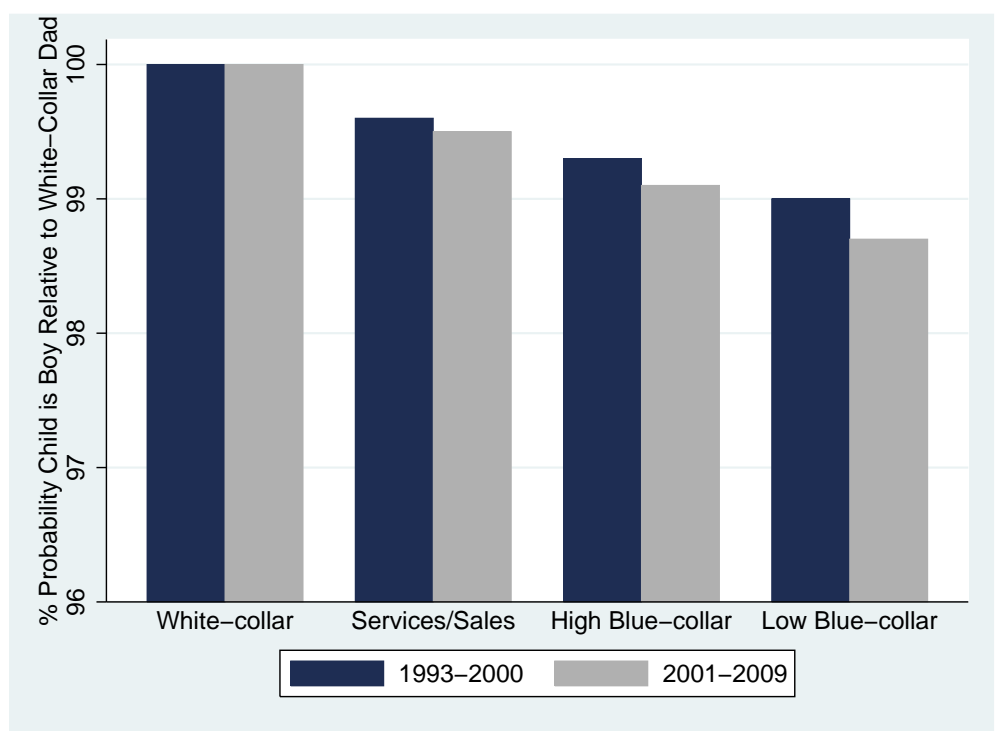

Notes: See Figure 3. 
Figure 5: County or District Sex Ratio at Birth by Adult Sex Ratio (20-29), 2005
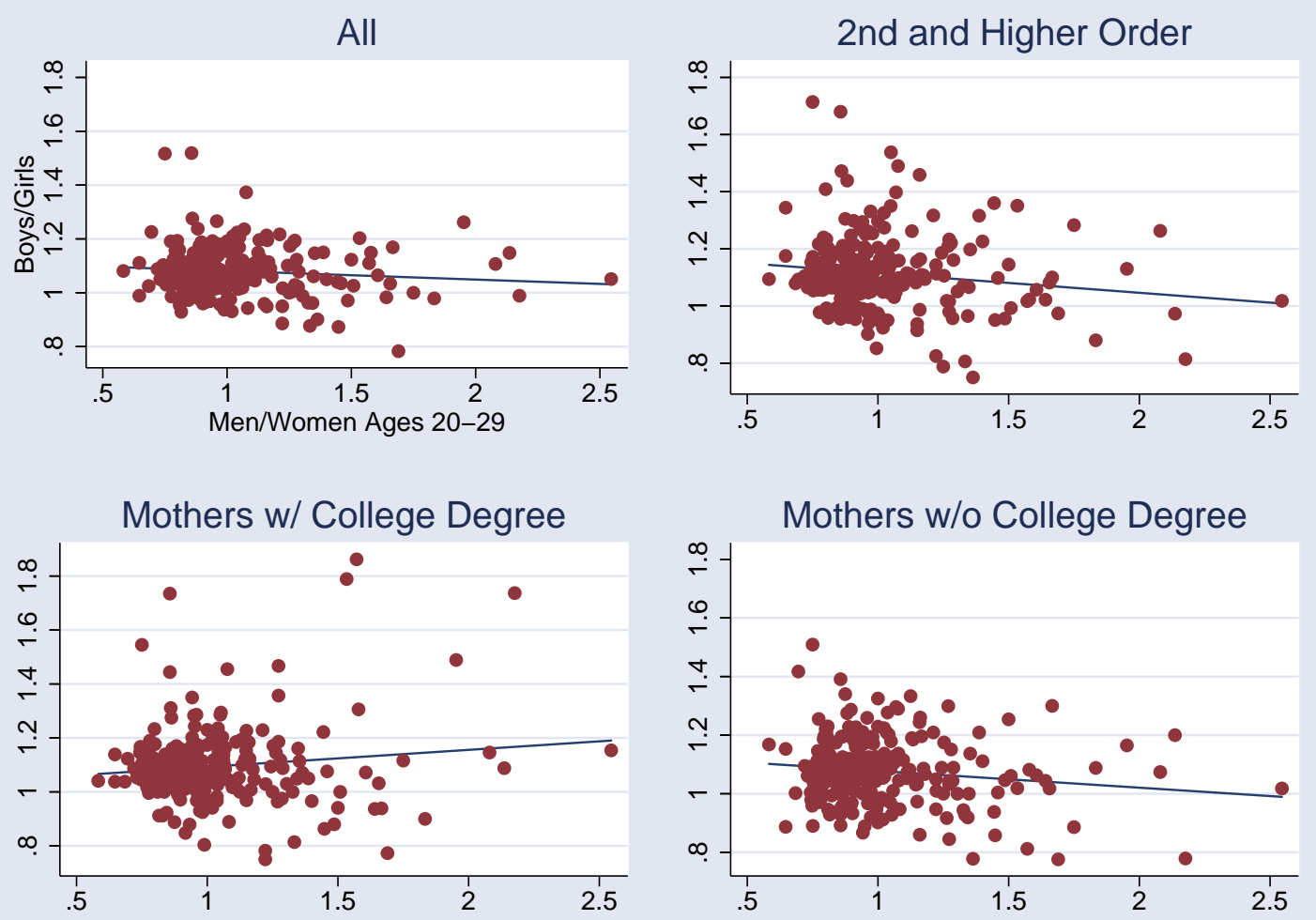

Source: Micro sample of the 2005 Vital Statistics of Korea: Birth; and 2\% micro sample of the 2005 Korean Census.

Note: County or district with 100 or more births (249 in total). 
Table 1: Offspring Sex Ratio and Maternal Education - A Changing Pattern

\begin{tabular}{|c|c|c|c|c|c|c|}
\hline \multirow[b]{3}{*}{ Education } & \multicolumn{6}{|c|}{ Birth Cohort } \\
\hline & \multicolumn{2}{|c|}{$1931-40$} & \multicolumn{2}{|c|}{$1941-50$} & \multicolumn{2}{|c|}{ 1951-60 } \\
\hline & Percent & Sex Ratio & Percent & Sex Ratio & Percent & Sex Ratio \\
\hline Primary or less & 82.3 & 1.098 & 55.7 & 1.086 & 20.6 & 1.044 \\
\hline Middle school & 8.9 & 1.079 & 20.6 & 1.075 & 25.9 & 1.105 \\
\hline High school & 6.7 & 1.052 & 17.7 & 1.079 & 39.9 & 1.090 \\
\hline College & 2.2 & 1.050 & 6.0 & 1.066 & 13.5 & 1.115 \\
\hline \multirow[t]{2}{*}{ Sum } & 100 & & 100 & & 100 & \\
\hline & \multicolumn{6}{|c|}{ Education classification based on relative standing } \\
\hline Low & 38.9 & 1.100 & 55.7 & 1.086 & 46.6 & 1.075 \\
\hline Mid & 43.4 & 1.095 & 20.6 & 1.075 & 39.9 & 1.090 \\
\hline High & 17.7 & 1.066 & 23.7 & 1.076 & 13.5 & 1.115 \\
\hline Sum & 100 & & 100 & & 100 & \\
\hline
\end{tabular}

Source: Computed from the $2 \%$ micro sample of the 2005 census.

1931-40: Low (no schooling); Middle (primary school); High (middle school or higher)

1941-50: Low (primary school or lower); Mid (middle school), High (high school or higher)

1951-60: Low (middle school or lower); Mid (high school); High (college or higher) 
Table 2: Parental Characteristics and Probability of Son, Years 1993-2009, Logistic Regression

\begin{tabular}{|c|c|c|c|c|c|c|}
\hline & \multicolumn{6}{|c|}{ Sample Period (mean): } \\
\hline & \multicolumn{3}{|c|}{$1993-2000(0.529)$} & \multicolumn{3}{|c|}{$2001-2009(0.518)$} \\
\hline & $\partial P^{\text {son }} / \partial x$ & $p$-value & Odds-ratio & $\partial P^{\text {son }} / \partial x$ & $p$-value & Odds-rat \\
\hline & \multicolumn{6}{|c|}{ A. Mother's Education } \\
\hline College & NI & & & NI & & \\
\hline High School & -0.0038 & 0.0272 & 0.995 & -0.0064 & 0.0017 & 0.994 \\
\hline Middle School & -.01174 & $<0.0001$ & 0.972 & -0.0323 & $<0.0001$ & 0.968 \\
\hline Mother's Age & -0.0105 & $<0.0001$ & 1.001 & -0.0010 & 0.0002 & 0.999 \\
\hline \multicolumn{7}{|l|}{ Parity } \\
\hline $1 \mathrm{st}$ & NI & & & NI & & \\
\hline $2 \mathrm{nd}$ & 0.0438 & 0.0007 & 1.045 & 0.0119 & $<0.0001$ & 1.012 \\
\hline $3 \mathrm{rd}$ & 0.4684 & $<0.0001$ & 1.597 & 0.2008 & $<0.0001$ & 1.222 \\
\hline 4 th + & 0.6316 & $<0.0001$ & 1.880 & 0.2512 & $<0.0001$ & 1.286 \\
\hline$N$ & $4,746,576$ & & & $4,273,016$ & & \\
\hline$-2 \log \mathrm{L} \mathrm{w} / \mathrm{o}$ covariates & $6,563,481$ & & & $5,917,868$ & & \\
\hline$-2 \mathrm{Log} \mathrm{L} \mathrm{w} /$ covariates & $6,542,105$ & & & $5,914,031$ & & \\
\hline \multirow[t]{2}{*}{$\chi^{2}$} & 20,805 & $<0.0001$ & & 3,817 & $<0.0001$ & \\
\hline & \multicolumn{6}{|c|}{ B. Father's Occupation* } \\
\hline White Collar & NI & & & NI & & \\
\hline Service/Sales & -0.0038 & 0.1194 & 0.996 & -0.0047 & 0.0559 & 0.995 \\
\hline Higher blue-collar & -0.1174 & 0.0053 & 0.993 & -0.0095 & 0.0181 & 0.991 \\
\hline Lower blue-collar & -0.0105 & 0.0076 & 0.990 & -0.0126 & 0.0051 & 0.987 \\
\hline Mother's Age & 0.001 & 0.0008 & 1.001 & -0.0010 & 0.0007 & 0.999 \\
\hline \multicolumn{7}{|l|}{ Parity } \\
\hline $1 \mathrm{st}$ & NI & & & NI & & \\
\hline 2 nd & 0.0457 & $<0.0001$ & 1.047 & 0.0113 & $<0.0001$ & 1.011 \\
\hline $3 r d$ & 0.4904 & $<0.0001$ & 1.633 & 0.2094 & $<0.0001$ & 1.223 \\
\hline 4 th + & 0.6736 & $<0.0001$ & 1.961 & 0.2451 & $<0.0001$ & 1.278 \\
\hline$N$ & $4,344,489$ & & & $3,885,319$ & & \\
\hline$-2 \log \mathrm{L} \mathrm{w} / \mathrm{o}$ covariates & $6,008,299$ & & & $5,380,940$ & & \\
\hline -2LogL w/ covariates & $5,987,792$ & & & $5,377,270$ & & \\
\hline$\chi^{2}$ & 19,901 & $<0.0001$ & & 3,649 & $<0.0001$ & \\
\hline
\end{tabular}

Source: Micro data on Korean Vital Statistics from 1993 to 2009.

"NI" denotes "not included (omitted category)." "Middle School" denotes middle school education or less.

* - the sample is limited to newborns whose fathers reported non-farm occupations. 
Table 3: Descriptive Statistics

\begin{tabular}{lcc}
\hline \hline & Mean & Standard Deviation \\
\hline ratio2029 & 1.02 & 0.277 \\
singlemale3544 & 0.182 & 0.059 \\
Christian (share) & 0.254 & 0.094 \\
Earnings (log) & 5.209 & 0.249 \\
Female/male employment & 0.636 & 0.116 \\
Housing value & 13.71 & 0.666 \\
\hline \hline
\end{tabular}

Source: Measures of sex ratios (dependent variables) were computed from the 2005 Vital Statistics for Birth and Death; the sex ratio of the population aged 20 to 29 and the proportion Christians are from the 2005 Population and Housing Census; and the average earnings from the 2005 Occupational Employment Statistics. 
Table 4: Correlates of County Sex Ratios, OLS

\begin{tabular}{|c|c|c|c|c|}
\hline & \multicolumn{4}{|c|}{ Dependent variable: Sex Ratio at Birth } \\
\hline & \multicolumn{4}{|c|}{ All births } \\
\hline ratio2029 & $\begin{array}{l}-0.045 \\
(0.028)\end{array}$ & $\begin{array}{c}-0.036 \\
(0.087)\end{array}$ & $\begin{array}{c}-0.044 \\
(0.056)\end{array}$ & \\
\hline singlemale3544 & & & & $\begin{array}{l}-0.237 \\
(0.019)\end{array}$ \\
\hline Earnings $(\log )$ & $\begin{array}{c}0.031 \\
(0.183)\end{array}$ & $\begin{array}{c}0.022 \\
(0.359)\end{array}$ & $\begin{array}{c}0.033 \\
(0.212)\end{array}$ & $\begin{array}{c}0.007 \\
(0.781)\end{array}$ \\
\hline Female/male employment & & $\begin{array}{c}-0.079 \\
(0.157)\end{array}$ & & \\
\hline Housing value & & & $\begin{array}{l}-0.007 \\
(0.476)\end{array}$ & \\
\hline Constant & $\begin{array}{c}1.012 \\
(0.000)\end{array}$ & $\begin{array}{c}1.106 \\
(0.000)\end{array}$ & $\begin{array}{c}1.087 \\
(0.000)\end{array}$ & $\begin{array}{l}1.124 \\
(0.000)\end{array}$ \\
\hline$R^{2}$ & 0.0456 & 0.0534 & 0.0354 & 0.0394 \\
\hline & & 2nd and & higher bi & \\
\hline ratio2029 & $\begin{array}{l}-0.094 \\
(0.002)\end{array}$ & $\begin{array}{c}-0.076 \\
(0.016)\end{array}$ & $\begin{array}{c}-0.117 \\
(0.000)\end{array}$ & \\
\hline singlemale3544 & & & & $\begin{array}{l}-0.401 \\
(0.009)\end{array}$ \\
\hline Earnings (log) & $\begin{array}{c}0.032 \\
(0.367)\end{array}$ & $\begin{array}{c}0.013 \\
(0.719)\end{array}$ & $\begin{array}{c}0.035 \\
(0.388)\end{array}$ & $\begin{array}{l}-0.003 \\
(0.934)\end{array}$ \\
\hline Female/male employment & & $\begin{array}{c}-0.162 \\
(0.050)\end{array}$ & & \\
\hline Housing value & & & $\begin{array}{l}-0.027 \\
(0.051)\end{array}$ & \\
\hline Constant & $\begin{array}{c}1.126 \\
(0.000)\end{array}$ & $\begin{array}{c}1.319 \\
(0.000)\end{array}$ & $\begin{array}{c}1.513 \\
(0.000)\end{array}$ & $\begin{array}{c}1.279 \\
(0.000)\end{array}$ \\
\hline$R^{2}$ & 0.0638 & 0.0784 & 0.110 & 0.059 \\
\hline
\end{tabular}

Notes: $p$-values in parentheses.

All regressions include the share Christian.

The level of aggregation is county or district and the number of observations is 249 .

ratio2029 - males over females, ages 20-29.

singlemale3544 - the number of single males aged 35 to 44 divided by the number of all males aged 35 to 44 in each county (or district) .

Housing value is in won $/ \mathrm{m}^{2}$, logged.

Source: Measures of sex ratios (dependent variables) were computed from the 2005 Vital Statistics for Birth and Death; the sex ratio of the population aged 20 to 29 and the proportion Christians are from the 2005 Population and Housing Census; and the average earnings from the 2005 Occupational Employment Statistics. 
Table 5: Correlates of County Sex Ratios, OLS

\begin{tabular}{|c|c|c|c|c|}
\hline \multirow[b]{3}{*}{ ratio2029 } & \multicolumn{4}{|c|}{$\begin{array}{l}\text { Dependent variable: Sex Ratio at Birth } \\
\begin{array}{ll}(1) & (2)\end{array}\end{array}$} \\
\hline & \multicolumn{4}{|c|}{ Mom: Not college educated } \\
\hline & $\begin{array}{l}-0.072 \\
(0.006)\end{array}$ & $\begin{array}{l}-0.055 \\
(0.042)\end{array}$ & $\begin{array}{l}-0.072 \\
(0.012)\end{array}$ & \\
\hline singlemale3544 & & & & $\begin{array}{l}-0.470 \\
(0.000)\end{array}$ \\
\hline Earnings (log) & $\begin{array}{c}0.056 \\
(0.066)\end{array}$ & $\begin{array}{c}0.038 \\
(0.222)\end{array}$ & $\begin{array}{c}0.046 \\
(0.164)\end{array}$ & $\begin{array}{l}-0.003 \\
(0.922)\end{array}$ \\
\hline Female/male employment & & $\begin{array}{l}-0.155 \\
(0.030)\end{array}$ & & \\
\hline Housing value & & & $\begin{array}{l}-0.009 \\
(0.455)\end{array}$ & \\
\hline Constant & $\begin{array}{c}0.927 \\
(0.000)\end{array}$ & $\begin{array}{l}1.111 \\
(0.000)\end{array}$ & $\begin{array}{c}1.083 \\
(0.000)\end{array}$ & $\begin{array}{l}1.226 \\
(0.000)\end{array}$ \\
\hline$R^{2}$ & 0.06 & 0.078 & 0.045 & 0.066 \\
\hline & & Mom: $\mathrm{Cc}$ & lege edu & \\
\hline ratio2029 & $\begin{array}{c}0.047 \\
(0.165)\end{array}$ & $\begin{array}{c}0.034 \\
(0.328)\end{array}$ & $\begin{array}{c}0.055 \\
(0.132)\end{array}$ & \\
\hline singlemale3544 & & & & $\begin{array}{c}0.185 \\
(0.274)\end{array}$ \\
\hline Earnings (log) & $\begin{array}{c}-0.014 \\
(0.720)\end{array}$ & $\begin{array}{l}-0.000 \\
(0.989)\end{array}$ & $\begin{array}{c}0.007 \\
(0.864)\end{array}$ & $\begin{array}{c}0.027 \\
(0.530)\end{array}$ \\
\hline Female/male employment & & $\begin{array}{l}-0.117 \\
(0.204)\end{array}$ & & \\
\hline Housing value & & & $\begin{array}{c}0.007 \\
(0.626)\end{array}$ & \\
\hline Constant & $\begin{array}{l}1.154 \\
(0.000)\end{array}$ & $\begin{array}{l}1.015 \\
(0.000)\end{array}$ & $\begin{array}{c}0.928 \\
(0.001)\end{array}$ & $\begin{array}{c}0.968 \\
(0.000)\end{array}$ \\
\hline$R^{2}$ & 0.025 & 0.032 & 0.023 & 0.020 \\
\hline
\end{tabular}

Notes: $p$-values in parentheses.

All regressions include the share Christian.

The level of aggregation is county or district and the number of observations is 249 .

ratio2029 - males over females, ages 20-29.

singlemale3544 - the number of single males aged 35 to 44 divided by the number of all males aged 35 to 44 in each county (or district) .

Housing value is in won $/ \mathrm{m}^{2}$, logged.

Source: Measures of sex ratios (dependent variables) were computed from the 2005 Vital Statistics for Birth and 58ath; the sex ratio of the population aged 20 to 29 and the proportion Christians are from the 2005 Population and Housing Census; and the average earnings from the 2005 Occupational Employment Statistics. 


\section{Appendix - For Online Publication}

\section{Demographic Background Korea}

The bride shortage projected for countries like India and China were evident in Korea already in the 1990s. Thus, the case could made that the current generation of parents are perhaps quite aware of the difficulties low status males have in finding partners.

Sex ratios decline through life because male mortality exceeds female such at every age. Absent sex discrimination, cohort sex ratios balance around age $20{ }^{20}$ Figure A-1 (in Appendix, as all tables and figures in this section) plots the population by age and gender in 2009. As can be seen, men outnumber women until age 55, indicating excess female mortality predating ultrasound screening [Goodkind, 1996]. This is not to say ultrasound had no impact. The male surplus is larger for the younger cohorts, especially those who were born in the late 1980s, early 1990s, some ten plus years following the introduction of the technology. This is further illustrated in Figure A-2 which plots the sex ratio by age.

What is also evident from Figure A-1 is a marked slowdown in fertility, which has further exacerbated the marriage squeeze facing Korean men, who on average marry women three years younger than themselves. ${ }^{21}$ The total fertility rate went from 6 in the 1960s, to 4.5 in 1970 to below replacement level in the early 1980s, and is now one of the lowest in the world at some 1.2 children per woman. ${ }^{22}$ Cohort sizes halved in the last three decades and thus

\footnotetext{
${ }^{20}$ The crossing-over normally happen around age 20. For instance, the US 1980 census counted 10,663 thousand males to 10,655 thousand females in the age group 20-24. Later censuses show slightly later crossing over points, a fact that might be driven by immigration.

${ }^{21}$ This age gap has been quite stable since 1990 .

${ }^{22}$ TFR was 1.08 in 2005; 1.13 in 2006; 1.26 in 2007 (Korea National Statistics Office, 2007 Annual Report on Live Births and Death Statistics).
} 
"surplus" men born in say 1980 seeking brides from the 1983 cohort face a sex ratio of 1.24, or a deficit of some 80,000 women, see Figure A-3.

Figure A-4 presents the gender gap among singles by age for the years 1985, 1995 and 2005 (drawn form the micro samples of the censuses). Since men marry women on average three years younger than themselves, at young ages, men outnumber women among the unmarried. As men move into prime marriage ages (and women out), the gap dwindles to eventually turn negative. In 1985, the number of single men and women balanced by age 34 . In 1995, parity is only reached at age 38 and in 2005, this age had been further pushed back to 44 - a change by 11 years despite the age at marriage only having moved by 3 years over the period. ${ }^{23}$

The deficit of women of marriageable age has visibly impacted marriage patterns. While in 1981, men were almost three times as likely to remarry as women, by the mid-90s, women had overtaken men, and in 2005 there were 1.5 more marriages between a remarrying bride and never-married groom, than the reverse combination, Figure A-5. ${ }^{24}$

Low status men have been the men hardest hit by the deficit of brides The percentage of males aged 35 to 44 who remained unmarried is negatively correlated with educational attainment and quality of occupation, Table A-7. (Interestingly, the results for females are nearly the opposite.)

Lately, Korean men unable to marry nationals have turned to poorer Asian countries for brides - the Philippines, Vietnam, Cambodia and China being major source countries. In 2006, 9 percent of marriages involved a foreign

\footnotetext{
${ }^{23}$ Male and female average age at first marriage was 27.8 and 24.8 respectively in 1990 and 31.1 and 28.1 in 2007.

${ }^{24}$ As a comparison, the fraction of marriages where it is the bride's first marriage but the groom's second or higher marriage was slightly lower than the reverse combination in the US, Statistical Abstract, 2000, table 145, covering the years 1970 to 1988.
} 
bride, up from less than one percent in 1990. Among men in agriculture or fishery, low status occupations, 41 percent of grooms married foreign women 2006. ${ }^{25}$ Although Korea's economic development has afforded even its poorest men brides, such foreign marriages have been warily received by a culturally and ethically homogenous society. ${ }^{26}$

\section{Bride price and old age support}

Korea adheres to the Confucian tradition in which it is the groom's (or rather, his parents') responsibility to provide housing for the newly-weds. In the case of the oldest son, this residence would be shared with his parents, an important form of old age support. Parents of daughters would see their daughters being provided for, but would not benefit from co-residence with prime-aged adults. Thus, while the tradition implies that the groom side contributes more resources to the new couple than the bride side, the implicit bride price only benefits the parents of daughters indirectly (their daughter and her children are provided for) and may leave them at a disadvantage in old age, a common feature of pre-industrial patriarchal societies [Das Gupta et al., 2003].

Over the last several decades, the advantage of sons over daughters became weaker as public old-age pension system was introduced and traditional social norms were gradually replaced by the Western-style individualism. ${ }^{27}$ For instance, the extended family has given way to the nuclear family reflected in a decline in co-residence with old-age parents and other forms of old-age support

\footnotetext{
${ }^{25}$ Vital Statistics of Korea, Marriage and Divorce.

${ }^{26}$ The topic of numerous newspaper articles, for instance, "Korean Men Use Brokers to Find Brides in Vietnam," The New York Times, February 22, 2007.

${ }^{27}$ The original old-age pension law was passed in 1973, although its implementation was postponed due to the oil crisis. The National Pension System was finally created in 1988 based on a new law passed in 1986, and its coverage expanded over the 1990s.
} 
Figure A-1: Population by Age and Gender, 2009

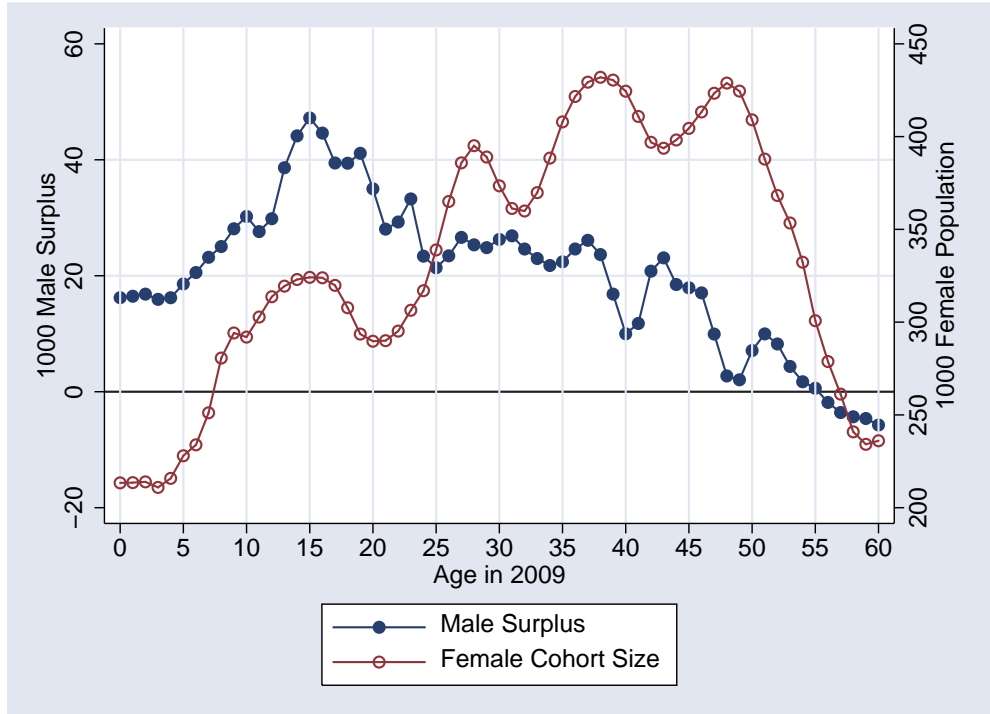

Source: 2009 Projected Population in Korea; Drawn from the website of Korean Statistical Information Service (http://www.kosis.kr).

Note: According to the Chinese zodiac, children born in the year of the Horse (12-year cycle) are independent and rebellious, characters considered particularly troublesome in daughters. Every 60 years, the year of the Fire Horse, these traits are exaggerated. The dates of the last Fire Horse occurred 21 January 1966 - 8 February 1967.

from child to parent (such as transfers). While these changes applied across the board, they may have been more important for the poor who relied more heavily on their sons for old age support.

Figure A-6 graphs the percent of elderly being primarily supported by their sons for support by education between 1994 and 2006. Two facts stand out. First, the less educated are more reliant on sons. In 1994, $70 \%$ of those with only primary education relied on sons, whereas the corresponding figure for those with a college education was slightly lower than $40 \%$. Second, in the relatively short period 1994-2006, there has been almost a halving in the reliance on sons, from close to $50 \%$ in 1994 to $27 \%$ in 2006. 
Figure A-2: Sex Ratio by Age, Korea and the US

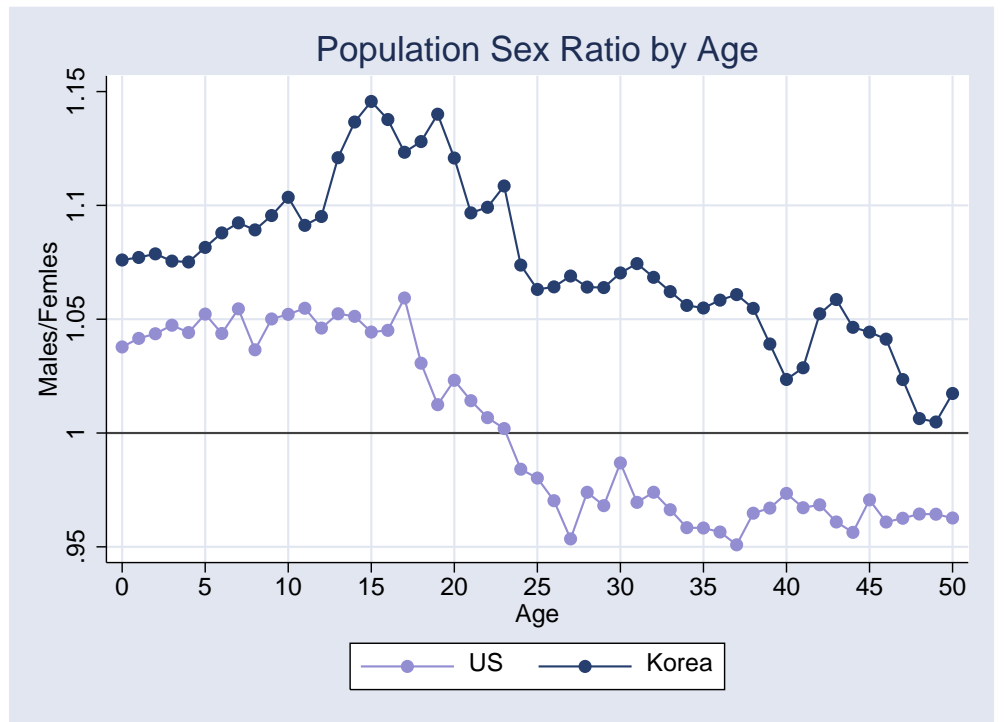

Source: For the US, 2000 Census. For Korea, 2009 Projected Population in Korea; Drawn from the website of Korean Statistical Information Service (http://www.kosis.kr).

Figure A-3: Sex Ratio by Age, 2009. Same cohort and lagged three years.

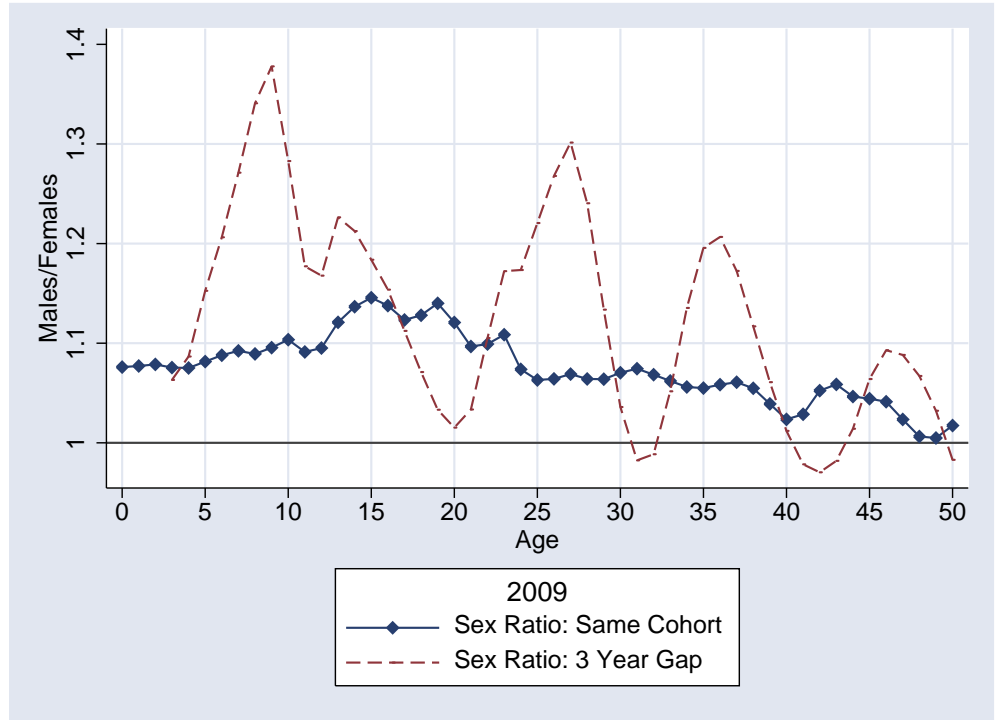

Source: 2009 Projected Population in Korea; Drawn from the website of Korean Statistical Information Service (http://www.kosis.kr). 
Figure A-4: Excess Single Men by Age, Various Census Years

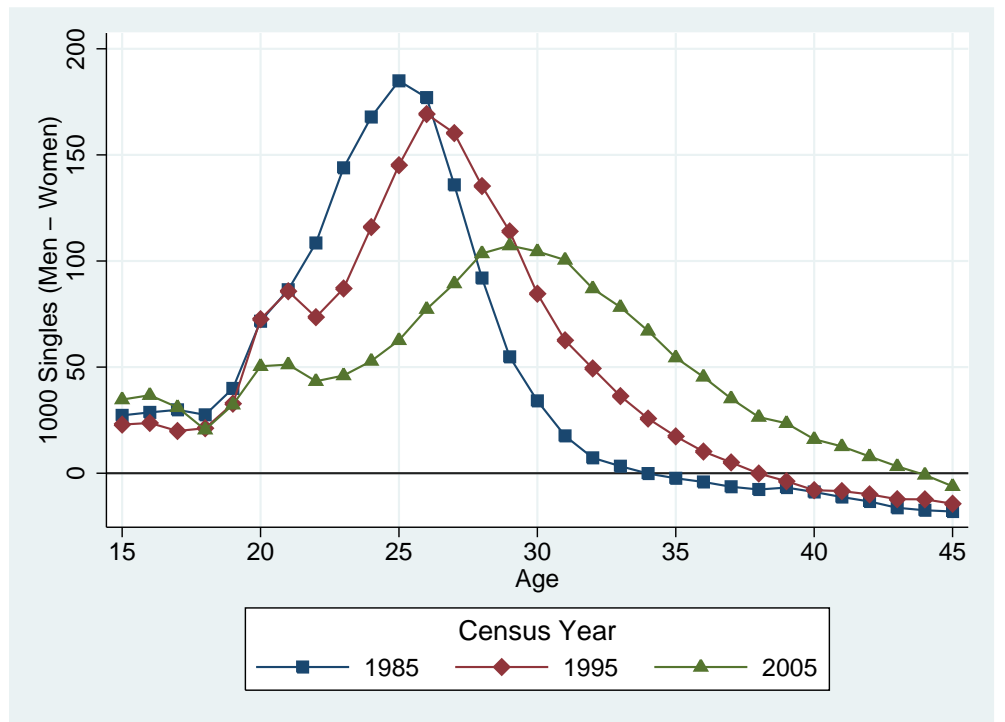

Source: 2\% micro samples of the 1985, 1995 and 2005 Korean Censuses.

Figure A-5: Number of marriages where one spouse was previously married, by year.

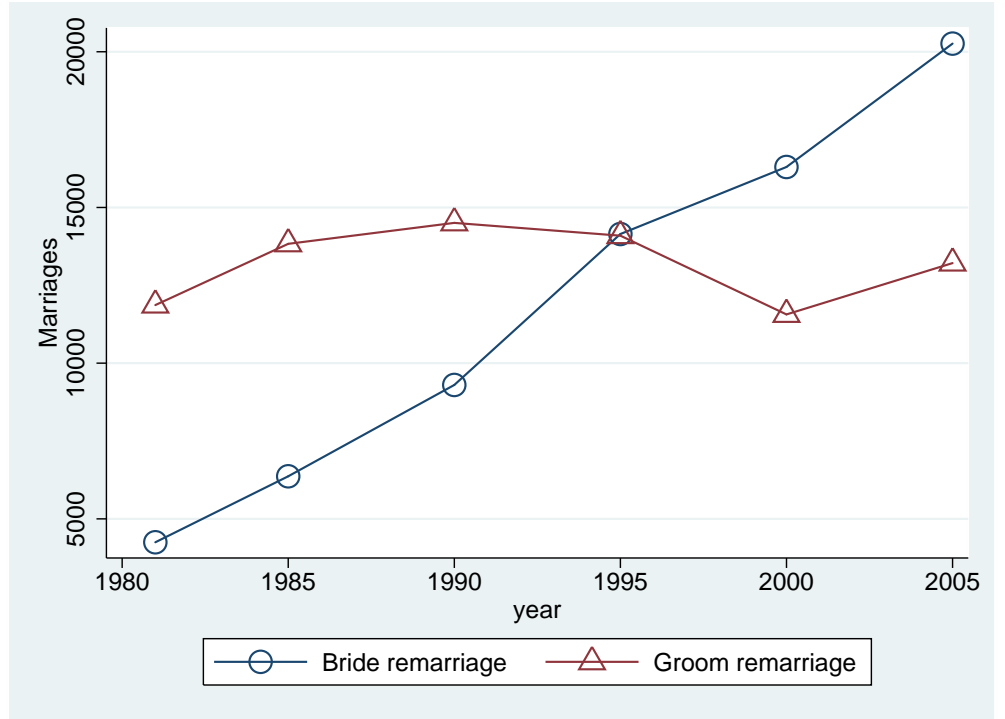

Source: Vital Statistics of Korea: Marriage and Divorce, each year; Drawn from the website of Korean Statistical Information Service (http://www. kosis.kr). 
Figure A-6: Reliance on Sons for Old Age Support, by Year and Education.

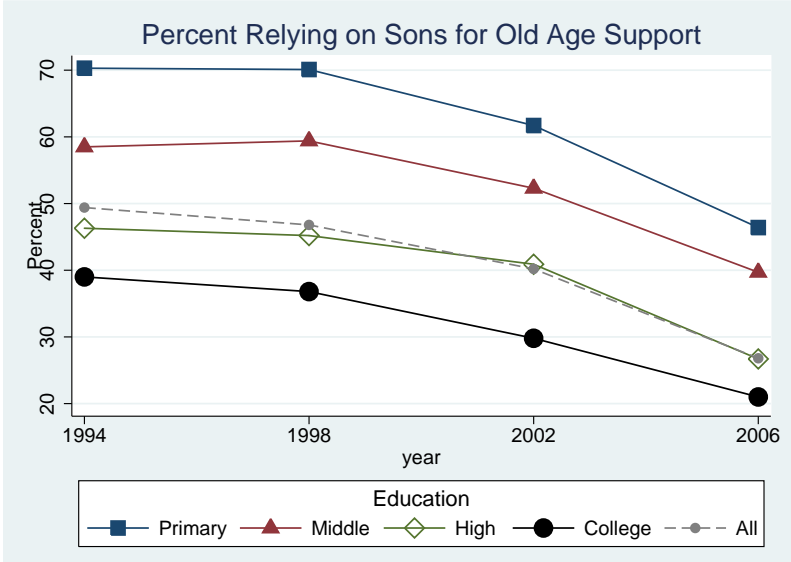

Source: Korean Statistical Office, Korean Social Statistics for each year. 
Table A-6: Completed fertility by maternal education and cohort

\begin{tabular}{lcccc}
\hline \hline & \multicolumn{4}{c}{ Parental Education } \\
\cline { 2 - 5 } Birth Year & Primary or less & Middle & High & College or higher \\
\hline $1931-1940$ & 4.339 & 3.604 & 3.215 & 2.919 \\
$1941-1950$ & 3.456 & 2.811 & 2.547 & 2.326 \\
$1951-1960$ & 2.551 & 2.199 & 2.017 & 1.928 \\
\hline \hline
\end{tabular}

Source: Korean 2005 Census, $2 \%$ micro sample.

Table A-7: Never Married, Ages 35-44

\begin{tabular}{lrrrrr}
\hline \hline & \multicolumn{2}{c}{ Men } & & \multicolumn{2}{c}{ Women } \\
\cline { 2 - 3 } \cline { 5 - 6 } & \multicolumn{2}{c}{ Percent } & & Percent \\
\hline Education: & & & & & \\
Primary or Lower & 1,803 & 39.05 & & 2,707 & 6.43 \\
Middle School & 4,370 & 26.18 & & 7,312 & 2.80 \\
High School & 33,501 & 15.54 & & 42,209 & 4.19 \\
College & 32,402 & 9.08 & & 23,220 & 7.31 \\
Graduate School & 4,905 & 6.32 & & 2,038 & 16.49 \\
All & 76,981 & 13.39 & & 77,486 & 5.40 \\
& & & & \\
Occupation: & & & & \\
Professional & 10,330 & 5.49 & & 4,940 & 11.96 \\
Clerical/Service/Sales & 30,029 & 7.96 & & 22,525 & 7.45 \\
Operatives & 20,661 & 12.45 & & 5,284 & 3.77 \\
Farmer & 3,233 & 21.16 & & 2,553 & 1.33 \\
Unskilled & 4,359 & 21.79 & & 2,493 & 3.57 \\
Not Working & 7,720 & 40.25 & & 39,578 & 3.98 \\
All & 76,332 & 13.45 & & 77,373 & 5.38 \\
\hline \hline
\end{tabular}

Source: Korean 2005 Census, $2 \%$ micro sample.

Individuals whose occupation was unclassified were excluded from the calculation. 


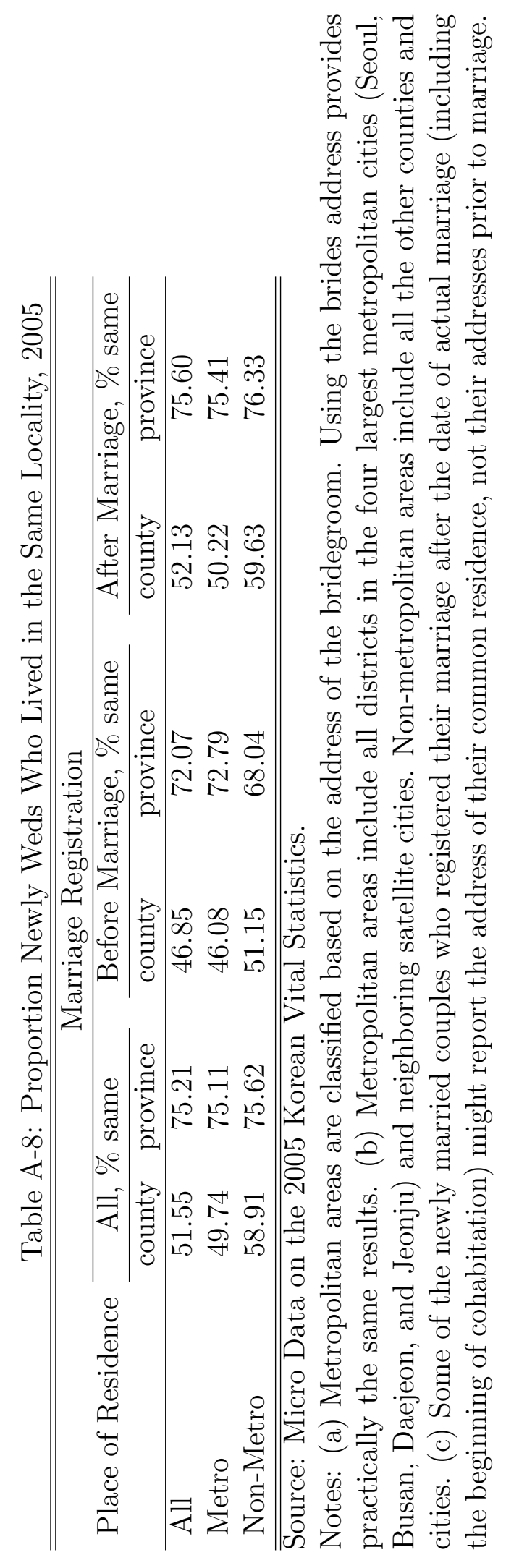




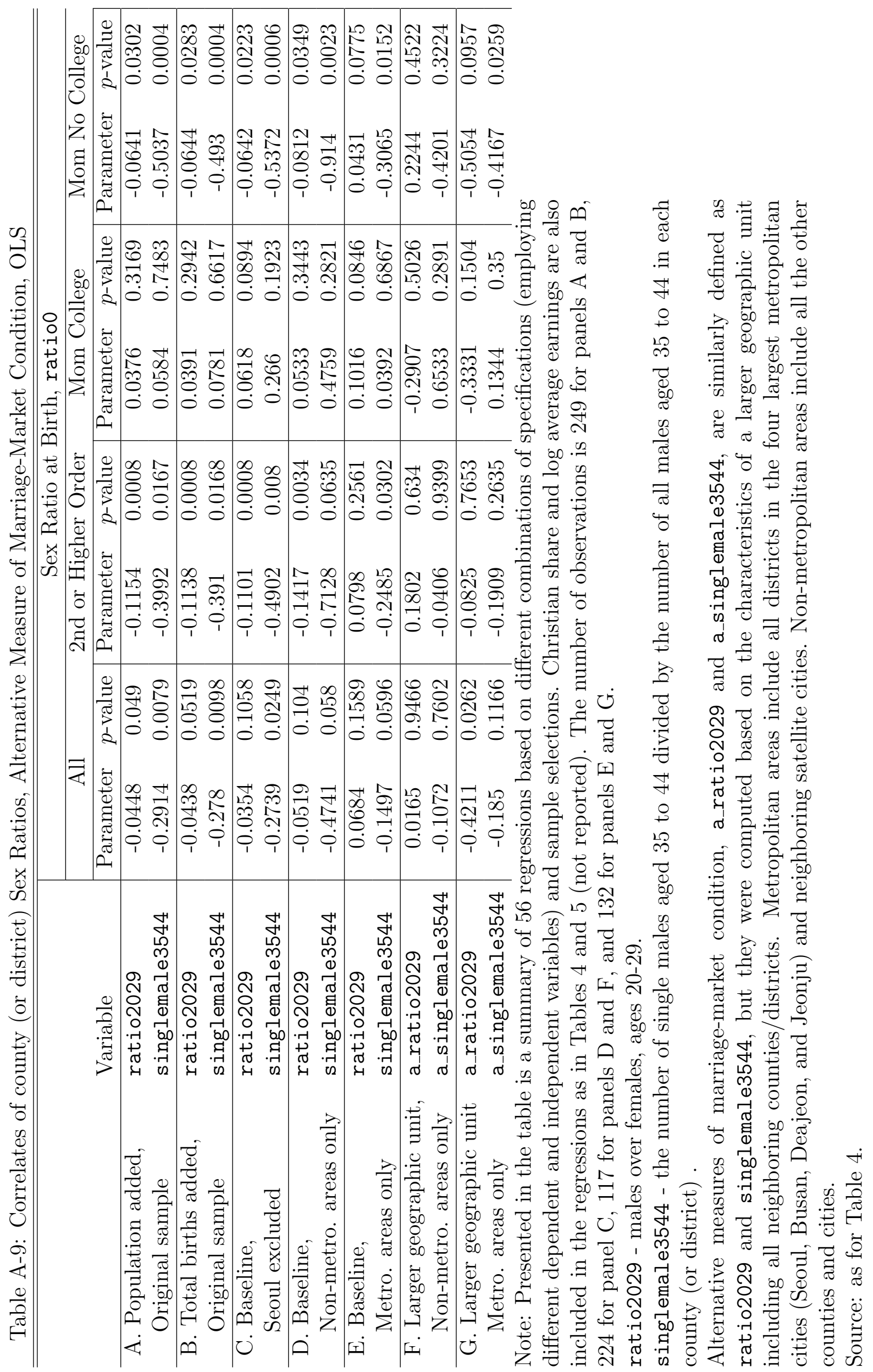

